\title{
Calculation of Longwave Radiation Fluxes in Atmospheres
}

\author{
E. M. Feigelson,' B. A. Fomin, ${ }^{2}$ I. A. Gorchakova, ${ }^{1}$ E. V. Rozanov, ${ }^{3}$ \\ Yu. M. Timofeyev, ${ }^{4}$ A. N. Trotsenko, ${ }^{2}$ And M. Daniel Schwarzkopf ${ }^{5}$
}

\begin{abstract}
A technique for the computation of longwave radiative quantities using the line-by-line approach has been developed in the Soviet Union. The method has been applied to obtain fluxes and cooling rates for standard atmospheric profiles used in the Intercomparison of Radiation Codes Used in Climate Models (ICRCCM) sponsored by the World Meteorological Organization. The sensitivity of the result to changes in the vertical quadrature scheme, the angular integration, and the spectral line shape is evaluated. Fluxes and cooling rates in the troposphere are in general agreement with those obtained with different line-by-line models. Results from parameterized models, including a wideband statistical model and one employing the integral transmission function, have been compared to the line-by-line results. Flux errors in the simplified schemes are of the order of $10 \mathrm{~W} / \mathrm{m}^{2}$. The sensitivity of these models to changes in atmospheric profiles, or to an increase in $\mathrm{CO}_{2}$ amount, is similar to that of the line-by-line calculations.
\end{abstract}

\section{INTRODUCTION}

Radiative heat exchange is a basic component of atmospheric energy transfer. The numerical models for weather forecasting, climate theory, cloud generation, and a number of mesoscale dynamic processes all invoke radiation codes to compute this quantity.

The radiative flux calculation algorithms in these models differ appreciably from each other and are always an approximation to the exact solutions of the radiative transfer equations. These approximations are needed because (1) the radiative calculations have to be made quickly compared to the calculation time of the model as a whole; (2) there is insufficient information in dynamic models to calculate the fluxes, and (3) the spatial, particularly the vertical, resolutions of the models are not sufficiently detailed.

The calculated fluxes in each model differ as a consequence of the distinctiveness of the specific algorithms, the initial data applied, the spectral resolutions, etc., of the model. We may thus ask how the results of the simulation of the dynamic processes in the atmosphere are affected by the differences in radiative flux calculation techniques in models. In order to settle this question, we have first attempted to clear up a simpler one: what accuracy can be achieved by means of the radiation codes used in the numerical models and the radiative transfer investigations conducted in the Soviet Union, and how do the fluxes calculated by these models agree with each other?

An initial intercomparison of the Soviet models was published in 1983 [Feigelson and Dmitrieva, 1983]. At about that time the Intercomparison of Radiation Codes Used in Climate Models (ICRCCM) study was initiated, directed by Fred Luther. Initial results, primarily for longwave clear-sky cases, have been published [Luther, 1984; Luther et al., 1988]. The ICRCCM reports include data from two Soviet

\footnotetext{
${ }^{1}$ Institute of Atmospheric Physics, Academy of Science, USSR.

${ }^{2}$ Kurchatov Institute of Atomic Energy, Moscow, USSR.

${ }^{3}$ Main Geophysical Observatory, Leningrad, USSR.

${ }^{4}$ Institute of Physics, Leningrad State University, USSR.

${ }^{5}$ NOAA Geophysical Fluid Dynamics Laboratory, Princeton, New Jersey.

Copyright 1991 by the American Geophysical Union.

groups headed by I. Karol and E. M. Feigelson. By including results from several line-by-line calculations, the ICRCCM reports make possible an estimate of the accuracy of calculations using less detailed techniques.

It is well-known [e.g., Kondratyev and Timofeyev, 1967] that line-by-line (LBL) flux calculations using monochromatic flux values derived from the transfer equation should give the most accurate results. This method does not require approximations in the radiative transfer physics, and the accuracy is essentially limited by two factors: (1) the errors in the initial spectroscopic data (i.e., fine-structure parameters of the absorption bands (positions, intensities, half widths of the spectral lines, shapes of the absorbing profile, etc.) and their dependence on the temperatures and pressures of absorbing and broadening gases; and (2) approximations made in the course of the development of the code used for the calculations.

The quality of the spectral line data is different for various parameters, gases, and bands. The completion of several extensive experimental and theoretical investigations of the fine-structure parameters, originally motivated by requirements for remote sensing of planetary atmospheres [Kondratyev and Timofeyev, 1978] has enabled the creation of large data compilations that are constantly being refined and improved [e.g., Rothman et al., 1987]. The fine-structure parameters are known with highest accuracy for the fundamental bands of $\mathrm{CO}_{2}, \mathrm{H}_{2} \mathrm{O}$, and $\mathrm{O}_{3}$. Further investigations in different spectral regions are required for validation and correction of the initial data.

The disadvantage of $\mathrm{LBL}$ calculations is that they require large computation times. As a result, their direct application is unsuitable in other (even one-dimensional) numerical atmospheric models. At present, these calculations are most useful as benchmarks for testing and improving approximate techniques. For this purpose, we have developed a line-byline numerical technique. This technique incorporates a number of new methods designed to improve the accuracy and speed of the LBL flux calculation. The basic results and the calculational details are discussed in section 2 of this paper. The LBL model is designated in this paper as the Kurchatov IAE model (or the IAE model).

Greater computational speed (compared to the LBL calculation) can be achieved by using band models, which employ transmission functions precomputed for specific 
spectral intervals. In different models, the width of the spectral intervals varies from $\sim 10$ to $100 \mathrm{~cm}^{-1}$. The models usually include the individual fundamental bands of $\mathrm{CO}_{2}$, $\mathrm{H}_{2} \mathrm{O}, \mathrm{O}_{3}$, etc., incorporating some of the details of the longwave radiative transfer in different bands. The transmissivities for the individual spectral regions are constructed on the basis of a combination of experimental and theoretical data. These techniques are widely used in one- and twodimensional atmospheric models; the most efficient techniques are applied in general circulation models.

A number of radiative transfer theory approximations are typically used in this approach, due to their computational efficiency, including (1) approximations for the inhomogeneous atmosphere (the "reduced mass" method, the CurtisGodson approximation, etc.), (2) use of the diffusivity factor instead of the angular integration, and (3) use of the "multiplication law" to account for overlapping of different gases within spectral bands. The errors induced by the use of these simplifications vary substantially from one band to another and depend upon the atmospheric profiles and upon the location of the flux levels. Results of the band model calculations and calculational aspects are discussed in section 3. The band model discussed in this paper will be referred to as the Main Geophysical Observatory-Leningrad State University (MGO-LSU) model.

The highest computational efficiency in the models to be discussed is achieved in calculations using the integral transmission function (ITF) approach [Feigelson, 1970, pp. 78-84]. This method further simplifies the description of longwave radiative transfer, primarily by not accounting for the temperature dependence of the atmospheric absorbers. The results obtained by means of the ITF calculation method are presented in section 4 .

The present paper thus describes results of longwave flux calculations for characteristic atmospheric profiles [McClatchey et al., 1972], based on the IAE, MGO-LSU, and ITF calculational techniques. Possible reasons for the disagreements of the parameterized models with the LBL results are analyzed.

\section{Line-By-Line Model Calculations}

\subsection{Basic Details of the Line-by-Line Integration}

The LBL method is a direct evaluation of the contribution of the individual lines of atmospheric absorption bands; it therefore is possible to obtain the longwave radiative fluxes with a spectral resolution potentially as fine as the monochromatic resolution. The accuracy of the obtained results is limited only by uncertainties in the initial data pertaining to the fine-structure line parameters and to the atmospheric profile. In practice, it is a serious computational problem to implement the LBL technique, owing to the great number of spectral lines and to the complex nature of the inhomogeneous atmosphere. Therefore the fundamental requirement imposed upon LBL models is to improve their computational efficiency while retaining the desired accuracy.

If information is available about the fine-structure parameters of the vibration/rotation bands of the molecular gases (line positions $\nu_{i}$, intensities $S_{i}$, half widths $\alpha_{i}$, and their dependence on pressure and temperature), the monochromatic volume absorption coefficient $k(\nu)$ at pressure $P$ and temperature $T$ can be evaluated by the formula

$$
k(\nu)=\sum_{j} \rho_{j}(P, T) \sum_{i} f_{i}^{j}(\nu)
$$

where $f_{i}^{j}(\nu)$ is the absorption profile (in $\mathrm{cm}^{2} / \mathrm{mol}$ ) of the $i$ th spectral line of the $j$ th absorbing gas and $\rho_{j}(P, T)$ is the density of the $j$ th absorbing gas (in $\mathrm{mol} / \mathrm{cm}^{3}$ ).

The principal idea in developing the computational technique for the IAE LBL model is the specification of the parameters determining the computational efficiency of calculations using (1) according to the accuracy desired for the results of the calculations. The selection of these parameters is based on physical considerations. Thus we may assume that computation of longwave fluxes due to weak lines requires less computation time than those due to strong (high-intensity) lines. We may therefore define a line absorption cutoff criterion $\varepsilon$, giving the minimum value of the absorption profile included for any line. This value may be used to determine the cutoff frequency for each line:

$$
\nu_{i}^{*} \leq f_{i}^{-1}(\varepsilon)
$$

where $\nu_{i}^{*}$ is the cutoff frequency for the $i$ th line, measured from the line center, and $f_{i}^{-1}$ is the inverse function of the absorption profile $f_{i}(\nu)$. A suitable value for $\varepsilon$ may readily be obtained by experimentation while calculating fluxes or transmittances. For homogeneous paths, where the transmission function may be approximated as $\exp \left(-e_{\nu} \rho L\right)$, the value of $\varepsilon$ can be estimated as

$$
\varepsilon \approx C_{R} \Delta e_{\nu} \approx C_{R} \frac{\delta_{\nu}}{\rho L}
$$

where $\delta_{\nu}$ is the acceptable relative error in the calculation of the transmission function for a homogeneous layer of width $L$ and density $\rho$, and $\Delta e_{\nu}$ the acceptable absolute error in the calculation of the molecular absorption coefficient $e(\nu)$ (in $\mathrm{cm}^{2} / \mathrm{mol}$ ) at the frequency $\nu . C_{R}$ is a constant with values ranging from 0.1 to 0.5 [Fomin et al., 1984]. Since $\nu_{i}^{*}$ differs for each spectral line, being large for strong lines and small for weak lines, accumulation of errors in computing the absorption coefficient using ( 1 ) is limited. For the strong water vapor and ozone lines, it may be that $\nu_{i}^{*}$ as determined by (2) is greater than the cutoff criterion of $10 \mathrm{~cm}^{-1}$; in that case, the line cutoff used is $10 \mathrm{~cm}^{-1}$.

When expressions (1)-(3) are applied, it is of great importance to represent correctly the shape of the absorption profile $f_{i}^{j}(\nu)$. In the present calculation the analytical approximation for the Voigt function of Matveyev [1972] is adopted:

$$
\begin{aligned}
f_{i}^{L D}= & \frac{S_{i}}{\alpha_{i}^{V}} C_{1}(1-\zeta) \exp \left(-\eta^{2} \ln 2\right)+\frac{S_{i}}{\alpha_{i}^{V}} \frac{\zeta}{1+\eta^{2}} \\
& -\frac{S_{i}}{\alpha_{i}^{V} \pi} \zeta(1-\zeta)\left(C_{2}+\zeta\right)\left[C_{3} \exp \left(-0.4 \eta^{2}\right)\right. \\
& \left.-\frac{1}{C_{4}-C_{5} \eta^{2}+\eta^{4}}\right]
\end{aligned}
$$

where

$$
\zeta=\frac{\alpha_{i}^{L}}{\alpha_{i}^{V}}, \quad \eta=\frac{\nu-\nu_{i}}{\alpha_{i}^{V}}
$$


$C_{1}=[(\ln 2) / \pi]^{1 / 2}, C_{2}=1+1.5 / \ln 2, C_{3}=0.066, C_{4}=$ 40.0, and $C_{5}=5.5$.

In the above expression, $\alpha_{i}^{V}$ is the Voigt half width of the $i$ th line having a Lorentz half width $\alpha_{i}^{L}$ and a Doppler half width $\alpha_{i}^{D}$. The Voigt half width is obtained using the following relation [Kondratyev and Timofeyev, 1970]:

$$
\begin{aligned}
& \alpha_{i}^{V}=\frac{1}{2}\left\{\alpha_{i}^{L}+\left[\left(\alpha_{i}^{L}\right)^{2}+4\left(\alpha_{i}^{D}\right)^{2}\right]^{1 / 2}\right\} \\
&+0.05 \alpha_{i}^{L}\left[1-\frac{2 \alpha_{i}^{L}}{\alpha_{i}^{L}+\left[\left(\alpha_{i}^{L}\right)^{2}+4\left(\alpha_{i}^{D}\right)^{2}\right]^{1 / 2}}\right]
\end{aligned}
$$

Deviations from the Doppler-Lorentz profiles in distant wings of lines are taken into account only for the lines in the $15-\mu \mathrm{m} \mathrm{CO}_{2}$ band, for which the empirical Benedict formulation is used, with parameters taken from Kunde and Maguire [1974]:

$$
\begin{gathered}
f_{i}(\nu)=f_{i}^{L D}(\nu) \quad\left|\nu-\nu_{i}\right|<3.5 \mathrm{~cm}^{-1} \\
f_{i}(\nu)=f_{i}^{L D}(\nu) \exp \left[-1.4\left(\left|\nu-\nu_{i}\right|-3.5\right)^{0.25}\right] \\
\left|\nu-\nu_{i}\right| \geq 3.5 \mathrm{~cm}^{-1}
\end{gathered}
$$

In all other calculations, the $f_{i}^{L D}(\nu)$ profile with a cutoff of $10 \mathrm{~cm}^{-1}$ was adopted. The two reasons for adopting this profile are, first, that there are no experimental relations comparable to (6) for the other atmospheric absorbers such as $\mathrm{H}_{2} \mathrm{O}$ and $\mathrm{O}_{3}$ and, second, that the profile may be used in conjunction with empirical relations from Roberts et al. [1976] to account for $\mathrm{H}_{2} \mathrm{O}$ continuum absorption. In addition, as shown below, the use of (6) in the $15-\mu \mathrm{m} \mathrm{CO}$ band does not strongly affect the accuracy of the flux calculations for the atmospheric profiles used in this study. For this reason, the relation (6) is not applied for $\mathrm{CO}_{2}$ calculations in the $4.3-\mu \mathrm{m}$ region and in any other bands.

The second principal feature of this technique is the shift in frequency of the line centers to the nearest frequency points (nodal points) at which the absorption coefficients are evaluated. This approach permits the use of a uniformly spaced frequency grid for the calculation, and permits substantial improvement in both the accuracy and the computational efficiency of the numerical frequency integration.

Figure 1 is a schematic illustration of this technique. If we let $h$ be distance (in frequency) between nodal points, and $\alpha_{i}$ the half width of line $i$, then, when $h$ assumes values between 1 and $3 \alpha_{i}$, a frequency integration over a region containing a line center not aligned with the nodal point (as in the left half of Figure 1) can lead to significant computational errors, since the absorption at the line center would not be properly sampled. This error is substantially alleviated by the shift of line centers to the nodal frequency points, as shown in the right half of Figure 1. An additional advantage is that the absorption profile $f_{i}^{L D}$ is now symmetrical with respect to the nodal point $\nu_{i}$, allowing a halving of the number of computations required for each line. In summary, this procedure substantially improves the accuracy of the integration, without requiring an undesirable decrease in the magnitude of frequency step $h$.

The determination of $h$ is done by computational experiment. It is important, however, to note that the errors introduced by the shift of lines (as well as by the integration procedure itself) may be controlled by reducing $h$ to values
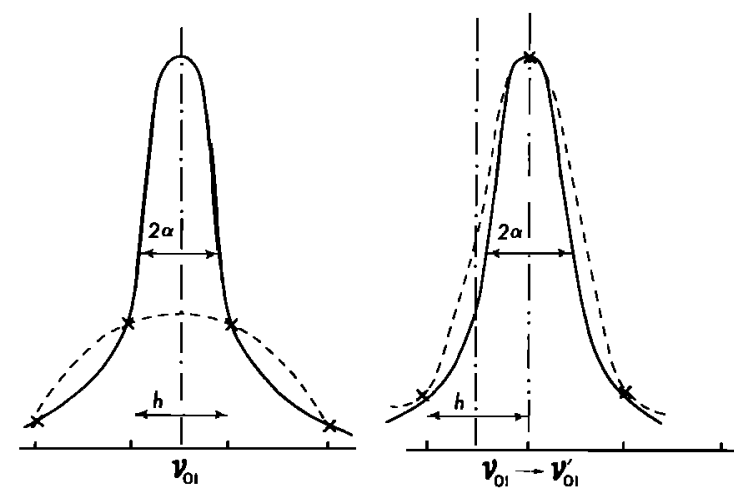

Fig. 1. Illustration of the shift of the line center position $\left(\nu_{0 i}\right)$ to the nodal point $\left(\nu_{0 i}^{\prime}\right) ; \alpha$ is the half width of the line, and $h$ the spacing of the frequency grid. The solid curve is the true profile of the absorption coefficient, the crosses are points where the absorption coefficients are calculated, and the dotted curve is the parabolic interpolation for the true absorption profile.

as small as a fraction of the Doppler half width [see Fomin et al., 1984; Trotsenko and Fomin, 1986]. It is also reasonable to assume that the small line shifts (of $0.01-0.03 \mathrm{~cm}^{-1}$ ) do not materially affect results of frequency integrations over spectral intervals of $1-5 \mathrm{~cm}^{-1}$ or greater. Experiments using various values of $h$, ranging from 0.2 to 2.5 times the mean Voigt half width indicate that differences in transmittances and fluxes are less than the absolute calculational error [Fomin et al., 1984]. An approximation for $h$ may be specified as

$$
h \approx k_{H} \alpha^{\sim V}
$$

where $\alpha^{-V}$ is the mean value of the Voigt half width at the specified pressure and temperature, and $k_{H}$ is a constant with value ranging from 1 to 3 [Fomin et al., 1984]. In practice, the values of $h$ actually used in flux calculations are 2-5 times smaller than those predicted from (7).

A deficiency in the direct application of (1)-(7) to flux computations is that, according to (2), a systematic underestimation of absorption occurs for "weak" lines, i.e., for the lines whose contributions to $e(\nu)$ are less than $\varepsilon$. In certain spectral regions, particularly the 8- to $13-\mu \mathrm{m}$ "window" region, this underestimation can markedly affect the accuracy of the calculation. In order to compensate for this effect, the simple technique given below is used.

If the $i$ th line is found to be "weak" (according to the above criterion), it should be possible to account for its intensity $S_{i}\left(=\int f_{i}^{L D}(\nu) d \nu\right)$ by replacing the real absorption profile $f_{i}^{L D}$ by a rectangular profile with a base proportional to $\alpha_{i}^{V}$. In practical applications, we exploit the fact that, according to (7), the grid step $h$ is roughly proportional to $\alpha_{i}^{V}$. Therefore one may apply the rectangular profile with the base extending over a frequency range of $2 h$ (centered on the line position) and a height of $S_{i} / 2 h$. Since $S_{i}$ and $\alpha_{i}$ are external model parameters, the inclusion of the weak lines does not significantly affect the computational efficiency of the model. In addition, the accuracy of the transmission function calculation is improved (at a specified $\varepsilon$ ) by a factor of up to 10 , as discussed below.

We begin by noting that the spectroscopic data compilation used here [Rothman, 1981] itself omits lines with intensities less than a criterion set differently for each absorbing gas. Therefore it is justifiable to consider transmission functions obtained by using (1)-(7) with $\varepsilon$ set to be a 

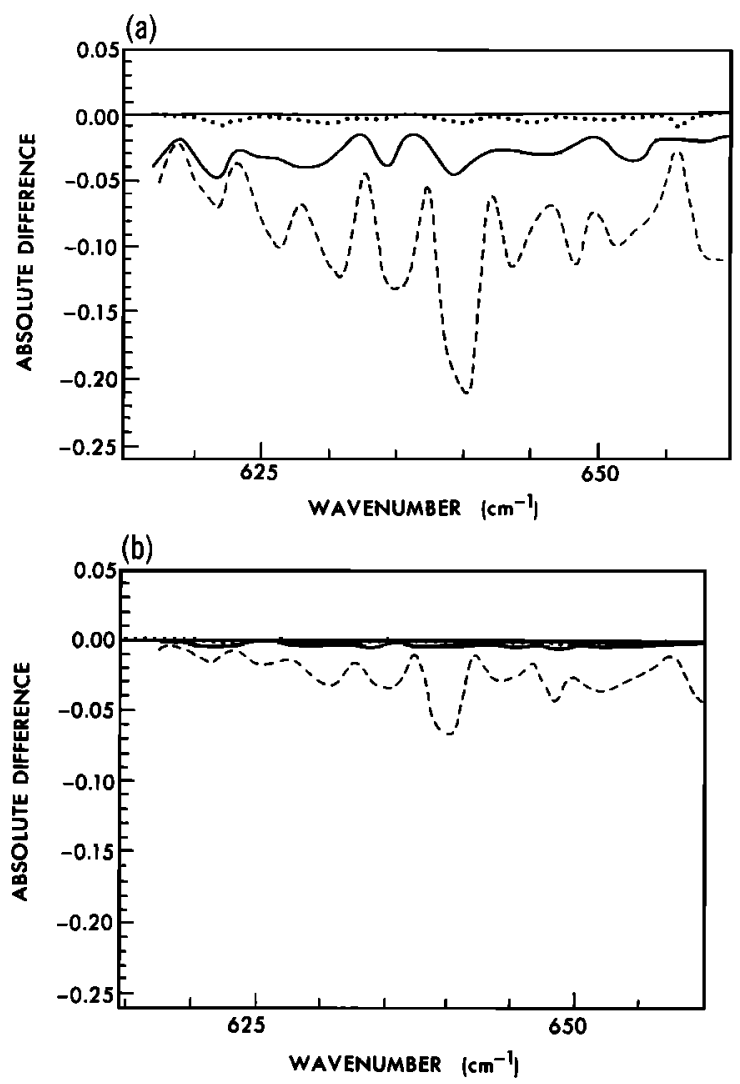

Fig. 2. Difference between "exact" transmission function and approximate calculations as a function of $\varepsilon$. Atmospheric conditions are $T=296 \mathrm{~K}$ and $P=0.1 \mathrm{~atm} ;$ absorbers are $\mathrm{CO}_{2}$ and $\mathrm{N}_{2}$. The dotted curve is for $\varepsilon=10^{-22} \mathrm{~cm}^{2} / \mathrm{mol}$, the solid curve is for $\varepsilon=$ $10^{-21} \mathrm{~cm}^{2} / \mathrm{mol}$, and the dashed curve is for $\varepsilon=10^{-20} \mathrm{~cm}^{2} / \mathrm{mol}$. Curves in Figure $2 a$ are results with no weak lines included; curves in Figure $2 b$ are results with weak lines included.

factor of 10 less than the criterion of the catalog as the reference ("exact") calculation, and to compare calculations using larger values of $\varepsilon$ to these transmissivities.

Results of these comparisons are shown in Figure 2 and Table 1. In the figure, transmission functions averaged over $1 \mathrm{~cm}^{-1}$ intervals in the $15-\mu \mathrm{m} \mathrm{CO}$ band are presented as a function of $\varepsilon$. Figure $2 a$ displays the spectral dependence of the absolute difference between the "exact" transmission function (as defined above) and transmission functions obtained using larger values of $\varepsilon$, when "weak" lines are not included; Figure $2 b$ is the corresponding figure, with weak lines included. The atmosphere is a homogeneous mixture of $\mathrm{CO}_{2}$ and $\mathrm{N}_{2}$ at $P=0.1$ atm and $T=296 \mathrm{~K}$. The $\mathrm{CO}_{2}$ content in the mixture is selected in such a way that the transmission functions averaged over $\Delta \nu_{i}$ would not be close to zero or 1 , in order to avoid the obvious cases of strong and weak absorption.

As a further comparison, the mean transmission function $(\bar{F})$ and the rms deviation of the calculated transmission functions from the "exact" values $\left(\chi^{2}\right)$, have been obtained for $\mathrm{CO}_{2}$ lines in the 620 - to $655-\mathrm{cm}^{-1}$ spectral region. Results for various values of $\varepsilon$, with and without "weak" lines are tabulated in Table 1. It is evident from both the table and the figure that at a specified $\varepsilon$, the inclusion of weak lines improves the accuracy of the calculation by a factor of 5-10.

The use of the above techniques for LBL calculations has been found to improve the computational efficiency of the calculation by a factor of 2-3 [Trotsenko and Fomin, 1986]. It should be emphasized that the parameters determining the efficiency of the $k(\nu)$ calculation, $\varepsilon$ and $h$, have a clear physical meaning because they are directly related to the fine-structure parameters of the absorption bands ( $S_{i}$ and $\alpha_{i}$ ). To obtain the desired computational accuracy, one may either reduce $\varepsilon$ and $h$, or specify the relative error $\delta_{\nu}$ for the transmission function ( $\varepsilon$ is proportional to $\delta_{\nu}$ according to (3)). The principal source of absolute error in the $k(\nu)$ calculations, in any case, is the error in the values of the fine-structure parameters.

It is evident that it would be desirable to validate the above LBL calculation technique by comparison with experimental results. For this purpose, we have employed measurements of $\mathrm{CO}_{2}$ transmission functions in the 4.3- and 15- $\mu \mathrm{m}$ bands [Bulanin and Tonkov, 1976] and of $\mathrm{O}_{3}$ absorptivity in the 9.3- $\mu \mathrm{m}$ bands [Bartman et al., 1975]. The results for $\mathrm{CO}_{2}$ are shown in Figure 3 and Table 2; corresponding results for $\mathrm{O}_{3}$ are in Figure 4 and Table 3. As these figures and tables show, the LBL technique gives good agreement with the experimental results in homogeneous atmospheres for both the transmission functions at particular frequencies and for frequency-integrated quantities. This agreement suggests that the simplifying assumptions used in the LBL calculations are valid for the homogeneous case, and that the spectroscopic data underlying the calculation are of high quality. It should be noted, however, that specific discrepancies are associated with a lack of information about the fine structure of some bands [Bulanin and Tonkov, 1976; Bartman et al., 1975].

\subsection{Line-by-Line Calculations in Inhomogeneous Atmospheres}

Radiative computations for the inhomogeneous atmosphere conventionally divide the atmosphere into a series of homogeneous layers with constant pressures, temperatures,

TABLE 1. Mean Transmission Functions $(\bar{F})$ and rms Deviation (in Percent) of Approximate Transmission Functions From the "Exact" Values $\left(\chi^{2}\right)$

\begin{tabular}{lcccccccc}
\hline & & \multicolumn{3}{c}{ Without Weak Lines } & & \multicolumn{3}{c}{ With Weak Lines } \\
\cline { 3 - 4 } \cline { 7 - 8 } \cline { 6 - 8 } & Exact & $\varepsilon=10^{-20}$ & $\varepsilon=10^{-21}$ & $\varepsilon=10^{-22}$ & & $\varepsilon=10^{-20}$ & $\varepsilon=10^{-21}$ & $\varepsilon=10^{-22}$ \\
\hline $\bar{F}$ & 0.3747 & 0.4356 & 0.3937 & 0.3766 & & 0.3943 & 0.3765 & 0.3747 \\
$\chi^{2}$ & & 8.5 & 2.7 & 0.3 & & 3.0 & 0.3 & 0.05 \\
\hline
\end{tabular}

The approximate calculations have different values of the line wing cutoff criterion $\varepsilon\left(\mathrm{cm}^{2} / \mathrm{mol}\right)$. The calculations are performed with and without inclusion of weak lines using the method given in section 2.1. The spectral interval is $620-655 \mathrm{~cm}^{-1}$, with $\mathrm{CO}_{2}$ lines only; $P=0.1 \mathrm{~atm}, T=296 \mathrm{~K}$. 


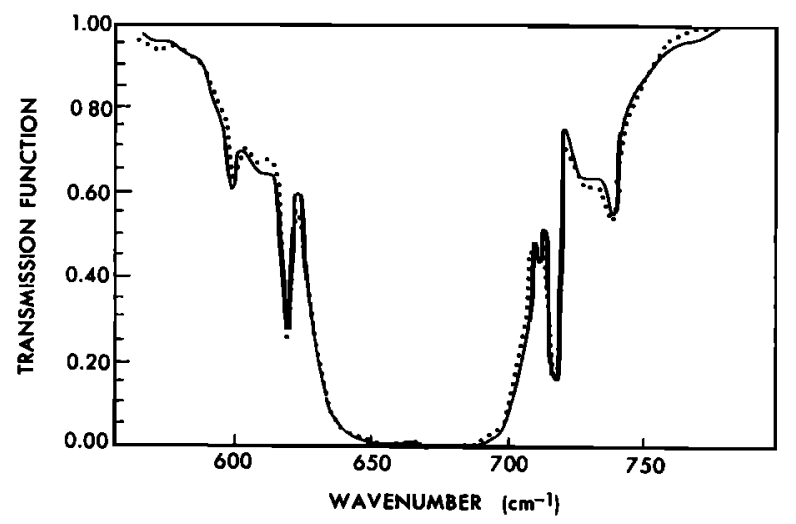

Fig. 3. Calculated and measured transmission function as a function of wavelength for conditions of $\mathrm{CO}_{2}: \mathrm{N}_{2}=1: 99, P=1 \mathrm{~atm}$, $T=293 \mathrm{~K}$, and $L=14.7 \mathrm{~m}$. The solid line gives the calculation, and the dotted line the experimental result. The spectral resolution of the measurements is $-3 \mathrm{~cm}^{-1}$.

absorber mixing ratios, and volume absorption coefficients. Although this approach facilitates the integration of radiative quantities over altitude, it is undesirable to adopt this method, since substantial problems develop in the accuracy of cooling rate and flux calculations [see Morcrette and Fouquart, 1985]. The problem is that the "step" interpolation of altitude-dependent quantities at layer boundaries can markedly perturb the actual altitude dependence of the absorbing and emitting properties of the atmosphere. This naturally affects the accuracy of the calculations, particularly in regions of strong absorption and of high-temperature gradients, e.g., the troposphere. The effects may be shown qualitatively using the rather obvious considerations given below.

In cases when atmospheric absorption is strong (i.e., the atmospheric emission is close to the blackbody function), longwave fluxes are generated at points in close proximity to the point at which they are being calculated. In such circumstances, the relative flux error due to the "homogeneous layer" approximation may be estimated by the following expression:

$$
\delta_{F} \approx 4 \frac{|\Delta T|}{\bar{T}}
$$

TABLE 2. Comparison of Transmission Functions for Homogeneous Paths Obtained by Using LBL Methods $\left(\bar{F}_{c}\right)$ and by Experiment $\left(\bar{F}_{e}\right)$

\begin{tabular}{cccccc}
\hline$T$, & $P$, & $L$, & & & \\
$\mathrm{K}$ & atm & $\mathrm{m}$ & $\chi^{2}$ & $\bar{F}_{\boldsymbol{e}}$ & $\bar{F}_{\boldsymbol{c}}$ \\
\hline 313 & 0.01 & 48.74 & $\mathbf{0 . 0 1 4}$ & $\mathbf{0 . 9 7 1}$ & $\mathbf{0 . 9 7 3}$ \\
293 & 1.00 & 14.7 & 0.021 & 0.562 & 0.563 \\
293 & 1.00 & 4.97 & 0.017 & 0.666 & 0.664 \\
293 & 0.05 & 4.97 & 0.018 & 0.971 & 0.973 \\
213 & 1.00 & 14.7 & 0.022 & 0.636 & 0.630 \\
\hline
\end{tabular}

The gaseous absorber is $\mathrm{CO}_{2}$, and the spectral interval is $580-780$ $\mathrm{cm}^{-1}$. Values for temperature $(T)$, pressure $(P)$, and path length $(L)$ are given. The $\mathrm{CO}_{2}$ mixing ratio is 0.01 and $\chi^{2}$ is the rms deviation between experimental and calculated transmissivities over the spectral interval. The experiments are described in greater detail by Bulanin and Tonkov [1976].

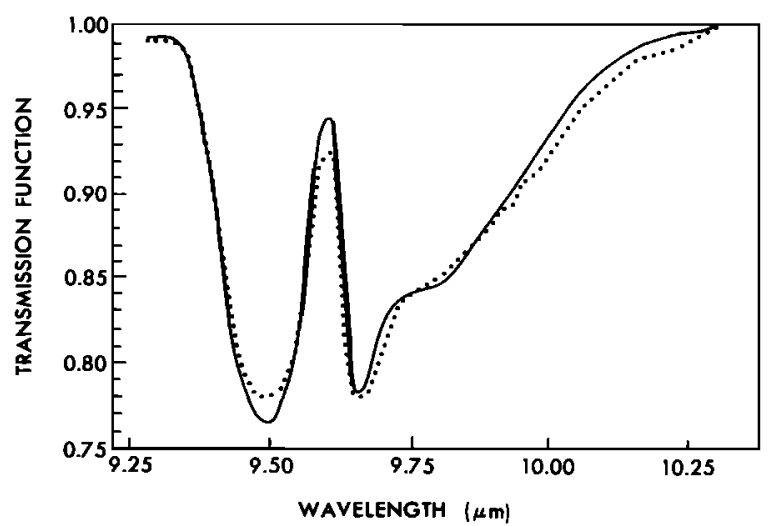

Fig. 4. Calculated and measured transmission function as a function of wave number for conditions of $\mathrm{O}_{3}: \mathrm{O}_{2}=3: 97, P=10.6$ $\mathrm{mm} \mathrm{Hg}, T=298 \mathrm{~K}, u=0.0665 \mathrm{~atm} \mathrm{~cm}_{\mathrm{STP}}$. The solid line gives the calculation, and the dotted line the experimental result. The spectral resolution of the measurements is $\sim 2 \mathrm{~cm}^{-1}$.

where $\bar{T}$ is the mean temperature of the nearest atmospheric layer and $\Delta T$ the absolute error caused by the introduction of the homogeneous layers. For standard atmospheric conditions [McClatchey et al., 1972] when the tropospheric temperature gradient is about $6 \mathrm{~K} / \mathrm{km}$, the introduction of homogeneous 0.5 - to $1.0-\mathrm{km}$-wide layers will result in values of $\delta_{F}$ of about 0.03-0.05. In turn, this can produce errors in frequency-integrated flux calculations of about several $\mathrm{W} / \mathrm{m}^{2}$. It is possible, in principle, to decrease $\delta_{F}$ by increasing the number of layers. However, this approach would greatly increase the computation time; in addition, the improvement in accuracy is difficult to estimate, owing to the complex nature of the changes in the absolute flux errors with resolution.

The computational technique adopted for the present calculations is therefore based on the interpolation of functions depending on $T$ and $k(\nu)$. This enables the calculation of fluxes and cooling rates to prespecified accuracy, limited only by the errors in the initial atmospheric data. A number of independent vertical interpolation grids are used in the present procedure; these will be described below.

In the first place, continuous interpolation is used to obtain altitude profiles of the initial data for the physical state of the atmosphere $(P, T, \rho$, etc.) taken from $M c$ Clatchey et al. [1972]. Although any interpolation scheme may be used here, in the present calculation, we have employed linear interpolation to facilitate intercomparison with other LBL techniques.

To interpolate the absorption coefficients $k_{y}$, we assume that at arbitrarily specified atmospheric levels $Z_{j}$, which

TABLE 3. Same as Table 2, Except that the Gaseous Absorber is $\mathrm{O}_{3}$ and the Spectral Interval is $9.2-10.4 \mu \mathrm{m}$

\begin{tabular}{|c|c|c|c|c|c|}
\hline $\begin{array}{l}T, \\
\mathrm{~K}\end{array}$ & $\begin{array}{c}P, \\
\mathrm{~mm} \mathrm{Hg}\end{array}$ & $\begin{array}{c}u, \\
\operatorname{atm} \mathrm{cm}\end{array}$ & $x^{2}$ & $\bar{F}_{e}$ & $\bar{F}_{c}$ \\
\hline 298 & 9.0 & 0.0250 & 0.008 & 0.941 & 0.946 \\
\hline 298 & 12.2 & 0.0490 & 0.012 & 0.898 & 0.903 \\
\hline 298 & 10.6 & 0.0665 & 0.011 & 0.893 & 0.899 \\
\hline
\end{tabular}

The absorber amount $u$ is given instead of the path length. The $\mathrm{O}_{3} / \mathrm{O}_{2}$ ratio is 0.03 . The experiments are described in greater detail by Bartman et al. [1975]. 
correspond to $P_{j}, T_{j}$, and $\rho_{j}$, volume monochromatic absorption coefficients $k_{\nu}\left(Z_{j}\right)$ are calculated by the LBL technique described in section 2.1. Then, for any atmospheric level $Z$, we may define

$$
k_{\nu}(Z)=\alpha_{\nu}^{j}+\beta_{\nu}^{j} \Psi(Z)
$$

where $Z_{j} \leq Z \leq Z_{j+1}, 1 \leq j \leq N$, and $N$ is the number of levels for this vertical interpolation. The $\Psi(Z)$ function could, in principle, contain additional information about the altitude dependence of $k(\nu)$; however, calculations made by Trotsenko and Fomin [1987] indicate that a linear function $(\Psi(Z)=Z)$ may be adopted in (9) without a significant loss of computational efficiency.

Regardless of the form of $\Psi(Z)$ employed, the coefficients $\alpha_{\nu}^{j}$ and $\beta_{\nu}^{j}$ are easily determined by using (9) at each nodal frequency point at altitudes $Z_{j}$ and $Z_{j+1}$. The number of levels to be used is determined by the specified accuracy of the calculation. In the calculation of fluxes, this technique achieves sufficient accuracy at $\Delta Z_{j}$ of about $1-5 \mathrm{~km}$ (depending on the altitude $Z$ ). This results in the use of about 50-60 vertical levels between $100 \mathrm{~km}$ and the surface.

The relation (9) may be applied to obtain the optical path length between $Z_{j}$ and $Z_{j+1}$ :

$$
\tau_{\nu}\left(Z_{j}, Z_{j+1}\right)=\alpha_{\nu}^{j}\left(Z_{j+1}-Z_{j}\right)+\beta_{\nu}^{j} \int_{Z_{j}}^{Z_{j+1}} \Psi(Z) d Z
$$

It should be noted that the integral in (10) is frequency independent; this enables the integral to be evaluated once, at any required degree of accuracy, in the application of this technique to practical computations. The value of employing (10) instead of the "step" interpolation is greatest at frequencies in the range of strong bands. At these frequencies, the variation of $k_{\nu}$ with altitude can reach as much as $\mathbf{0 . 5}$ $\mathrm{km}^{-1}$ [Trotsenko and Fomin, 1987], i.e.,

$$
\frac{1}{k_{\nu}} \frac{\delta k_{\nu}}{\delta Z} \sim 0.5 \mathrm{~km}^{-1}
$$

In local thermodynamic equilibrium, upward and downward fluxes may be computed in a narrow spectral interval $\Delta \nu$ at atmosphere level $\boldsymbol{H}$ by means of the following expressions:

$$
\begin{aligned}
& F_{\Delta \nu}^{+}(H)=2 \bar{B}\left(T_{s}\right) \int_{\Delta \nu} E_{3}\left[\tau_{\nu}(0, H)\right] d \nu \\
&+2 \int_{0}^{H} \bar{B}[T(Z)] \varphi_{H}(Z) d Z \\
& F_{\Delta \nu}^{-}(H)=2 \int_{H}^{Z_{N}} \bar{B}[T(Z)] \varphi_{H}(Z) d Z
\end{aligned}
$$

where

$\varphi_{H}(Z)=\int_{\Delta \nu} E_{2}\left(\left|\tau_{\nu}(0, H)-\tau_{\nu}(0, Z)\right|\right) k_{\nu}(Z) d \nu$

Here $F_{\Delta \nu}^{+}(H)$ and $F_{\Delta \nu}^{-}(H)$ are the upward and downward

\begin{tabular}{|c|c|}
\hline Parameter & Value \\
\hline Frequency integration & Varying $0.02-0.001$ \\
\hline Line cutoff criterion $\varepsilon, \mathrm{cm}^{2} / \mathrm{mol}$ & Varying $5 \times 10^{-25}$ to $1 \times 10^{-26}$ \\
\hline $\begin{array}{l}\text { Altitude grid step for } \bar{B}[T(Z)] \\
\text { calculation, } \Delta Z_{n}, \mathrm{~km}\end{array}$ & Constant 0.025 (4000 levels) \\
\hline $\begin{array}{l}\text { Altitude grid step for } k_{\nu}(Z) \\
\text { calculation, } \Delta Z_{\nu}, \mathrm{km}\end{array}$ & Varying $1.0-5.0$ (55 levels) \\
\hline $\begin{array}{l}\text { Altitude grid step for } \varphi_{H}(Z) \\
\text { interpolation, } \Delta Z_{v}, \mathrm{~km}\end{array}$ & Varying 0.05-1.0 (about 260 levels) \\
\hline
\end{tabular}
fluxes, respectively; $T_{s}$ and $Z_{N}$ are the surface temperature and the altitude of the effective top boundary of the atmo-
TABLE 4. Parameters Used in Numerical Approximations Employed in the LBL Algorithm Described in Sections 2.1 and 2.2

sphere, respectively; and $E_{2}$ and $E_{3}$ are exponential integrals. It is assumed that for the narrow spectral intervals of about $1 \mathrm{~cm}^{-1}$, the Planck function $B_{\nu}(T)$ may be considered constant and be replaced by the mean Planck function:

$$
\begin{aligned}
B_{\nu}(T) \approx \bar{B}_{\bar{\nu}}(T)=\left[3.7418 \times 10^{-8}(\bar{\nu})^{3}\right] / \\
\{\exp [(1.43868 \bar{\nu}) / T]-1\}
\end{aligned}
$$

where $\bar{\nu}$ is the mean frequency of the $\Delta \nu$ interval, and the Planck function is expressed in $\mathrm{W} / \mathrm{m}^{2}$.

Numerical integration of $(12)-(13)$ to obtain fluxes thus involves obtaining the Planck function $B[T(Z)]$ and the reconstruction of $\tau_{\nu}(Z)$ using (9)-(10). There is little difficulty in calculating $\bar{B}[T(Z)]$ even using the vertical grid with fine resolution $\left(Z_{p}\right)$ because the computation is done only once. As indicated in Table 4, a uniform vertical grid with 4000 levels $\left(\Delta Z_{p}=25 \mathrm{~m}\right)$ has been employed in the present calculations.

Calculations of the function $\varphi_{H}(Z)$ using the $Z_{p}$ grid are unsuitable, however, for two reasons. First, the $Z_{p}$ grid resolution is based on the emitting properties of the atmosphere. In certain cases (see (11)) this resolution may be too coarse to permit accurate absorptivity calculations. On the other hand, the evaluation of the $E_{2}$ integral is time consuming, even using special numerical procedures. As a result, it is necessary to compute $\varphi_{H}(Z)$ by an interpolation technique using a nonuniform and less detailed altitude grid $Z_{v}$. The final altitude integration remains over the $Z_{p}$ grid. In contrast to the "homogeneous layer" approach, the major computational problem in the evaluation of $\varphi_{H}(Z)$ occurs when $Z$ approaches $H$, since in this case the calculation involves the evaluation of $E_{n}(x)$ functions when $x \rightarrow 0$. In this situation, the $E_{n}(x)$ functions may not be expanded by Taylor's theorem, and common polynomial approximations of $\varphi_{H}(Z)$ converge slowly. Since $k_{\nu}$ may attain values as large as $10^{3} \mathrm{~km}^{-1}$ in frequency regions with strong atmospheric absorption, the accurate generation of $\varphi_{H}(Z)$ in the vicinity of $H$ requires the use of an altitude interpolation with a vertical resolution of $10^{-3}-10^{-5} \mathrm{~km}$ [Trotsenko and Fomin, 1987]. In contrast, when $Z$ is far from $H$, and in spectral regions when atmospheric absorption is weak, the $\varphi_{H}(Z)$ interpolation may be performed with a resolution of as much as $1-5 \mathrm{~km}$. In actual computations, it thus becomes necessary to perform the altitude interpolation over nonuniform grids which may contain a large number of vertical levels.

To solve this singularity problem, we exploit the fact that in frequency regions with strong absorption, the longwave 
fluxes at $\boldsymbol{H}$ are generated by exchange of photons in spatial regions close to $H$. In consequence, we can obtain analytical expressions for $F_{\Delta \nu}^{+}$and $F_{\Delta \nu}^{-}$in regions close to $H$, neglecting the altitude dependencies of some atmospheric parameters in these regions. Using these expressions, we can manipulate (12)-(13) in such a manner to obtain expressions in which the terms containing altitude integrals are a small correction to the flux values obtained from the other terms. In practice, we have used two sets of expressions.

In the first approach, we assume that in spatial regions close to $H$ the molecular absorption coefficients and the temperature are essentially constant, and the density of the atmospheric absorbers varies in altitude in the same manner as the atmosphere as a whole (assuming an isothermal layer in hydrostatic equilibrium):

$$
\rho(Z)=\rho(H) \exp \left(\frac{-(Z-H)}{R(H)}\right)
$$

Here $R(H)$ is proportional to $T(H)$. It then follows that $k_{v}(Z)$ varies in altitude in the same manner. Using the above relation, along with (15), we can define the following quantity

$$
\begin{gathered}
\varphi_{H}(Z) \approx \pi_{H}(Z) \equiv \frac{\bar{B}[T(H)]}{\bar{B}[T(Z)]} \\
\int_{\Delta \nu} k_{\nu}(H)\left(\frac{\rho(Z)}{\rho(H)}\right)\left\{E_{2}\left[k_{\nu}(H) R(H)\left(1-\left(\frac{\rho(Z)}{\rho(H)}\right)\right)\right] d \nu\right\}
\end{gathered}
$$

Using (17) and the exponential integral relations,

$$
\frac{d}{d \tau} E_{3}(\tau)=-E_{2}(\tau) \quad E_{3}(0)=1 / 2
$$

we can replace (12)-(13) with the relations

$$
\begin{aligned}
F_{\Delta \nu}^{+}= & \bar{B}[T(H)] \Delta \nu \\
& -2 \bar{B}[T(H)] \int_{\Delta \nu} E_{3}\left\{k_{\nu}(H) R(H)\right. \\
& \left.\cdot \exp \left[\left(H-Z_{N}\right) / R(H)\right]-1\right\} d \nu \\
& +2 \bar{B}\left(T_{s}\right) \int_{\Delta \nu} E_{3}\left[\tau_{\nu}(0, H)\right] d \nu \\
& +2 \int_{0}^{H} \bar{B}[T(Z)]\left[\varphi_{H}(Z)-\pi_{H}(Z)\right] d Z
\end{aligned}
$$

and

$$
\begin{aligned}
F_{\Delta \nu}^{-} & =\bar{B}[T(H)] \Delta \nu \\
& -2 \bar{B}[T(H)] \int_{\Delta \nu} E_{3}\left\{k_{\nu}(H) R(H)\right. \\
& \left.\cdot\left[1-\exp \left(\left(H-Z_{N}\right) / R(H)\right)\right]\right\} d \nu \\
& +2 \int_{H}^{Z_{N}} \bar{B}[T(Z)]\left[\varphi_{H}(Z)-\pi_{H}(Z)\right] d Z
\end{aligned}
$$

In the case of strong absorption, the contribution to the flux of the last terms in (19)-(20) is small compared to that of the other summands.

The second approach exploits the identity

$$
\begin{array}{r}
\int \bar{B}(Z) \varphi_{H}(Z) d Z \equiv \int[\bar{B}(Z) \\
-\bar{B}(H)] \varphi_{H}(Z) d Z \\
+\int \bar{B}(H) \varphi_{H}(Z) d Z
\end{array}
$$

By substitution of (21) into (12)-(13), and again exploiting (16) and (17), we obtain

$$
\begin{aligned}
F_{\Delta \nu}^{+}(H)= & \bar{B}[T(H)] \Delta \nu+2\left\{\bar{B}\left(T_{s}\right)\right. \\
& -\bar{B}[T(H)]\} \int_{\Delta \nu} E_{3}\left[\tau_{\nu}(H)\right] d \nu \\
& +2 \int_{0}^{H}\{\bar{B}[T(Z)]-\bar{B}[T(H)]\} \varphi_{H}(Z) d Z
\end{aligned}
$$

and

$$
\begin{aligned}
F_{\Delta \nu}^{-}(H)= & 2 \bar{B}[T(H)] \int E_{3}\left[\tau_{\nu}\left(Z_{N}, H\right)\right] d \nu \\
& +2 \int_{H}^{Z_{N}}\{\bar{B}[T(Z)]-\bar{B}[T(H)]\} \varphi_{H}(Z) d Z
\end{aligned}
$$

As in (19)-(20), the contributions to the flux of the last summands in (22)-(23) are small compared to that of the other terms. Furthermore, these last terms are smoother functions in altitude than the corresponding terms in (12)(13), thus facilitating the altitude integration. In practice, the expressions in (22)-(23) were used for calculations as the computational efficiency of this method is almost double that of the method employing (19)-(20). The latter equations were used, however, in testing the altitude integration principle (using the trapezoidal rule) and for the selection of the interpolation grid for $\varphi_{H}(Z)$.

As indicated above, the algorithms for computation of the upwelling and downwelling fluxes are designed primarily for spectral intervals containing strong absorption bands. Thus one would expect significant difficulties in the computation of these fluxes in other regions, since photon exchanges that generate flux at $H$ no longer occur in close vicinity to $H$. In practice, this caused difficulties in the selection of the altitude interpolation grid $\left(\Delta Z_{\nu}\right)$.

These difficulties are illustrated in Figures 5 and 6 . In Figure 5, the altitude dependence of $F_{\Delta \nu}^{+}(H)$ obtained using different $\Delta Z_{v}$ grids is presented for the $600-700 \mathrm{~cm}^{-1}$ spectral interval, a region with strong absorption. Figure 6 is the corresponding result for the $800-900 \mathrm{~cm}^{-1}$ interval, which has weak absorption. It is found that in the strong $15-\mu \mathrm{m} \mathrm{CO}_{2}$ band, the interpolation grid with 100 vertical levels is sufficient to produce flux results insensitive to increasing grid size. However, in the weak absorption band, a grid with 260 vertical levels is required to achieve good convergence. In practice, the latter grid has been applied at all frequencies, in order to give the algorithm greater applicability to a wide range of atmospheric conditions. 


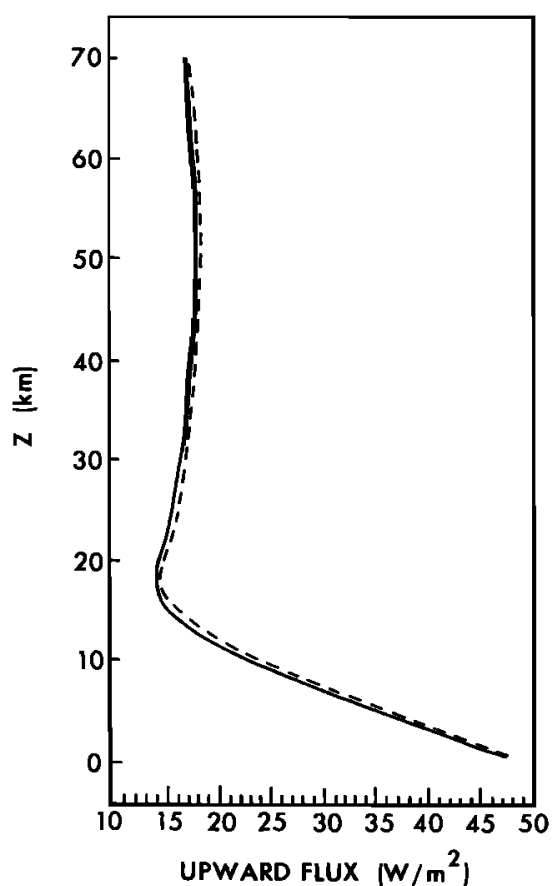

Fig. 5. Upward flux in the $600-700 \mathrm{~cm}^{-1}$ interval for the tropical profile, obtained with different $\varphi_{H}$ vertical interpolation grids. Gaseous absorbers are $\mathrm{H}_{2} \mathrm{O}$ (with continuum), $\mathrm{CO}_{2}(300 \mathrm{ppmv})$ and $\mathrm{O}_{3}$. Shown are the results using the $\Delta Z_{v}$ grid with 70 vertical levels (dashed curve) and with 130 vertical levels (dotted curve).

Table 4 is a summary of the various parameter settings and interpolation grids discussed in sections 2.1 and 2.2. The selection of the parameters is based on a requirement that flux calculations be accurate (compared to the "exact" methods) to about $0.2 \mathrm{~W} / \mathrm{m}^{2}$ over spectral regions of 100 $\mathrm{cm}^{-1}$, and to about $0.5 \mathrm{~W} / \mathrm{m}^{2}$ over the whole longwave spectrum.

\subsection{Results of LBL Calculations}

The methods described in sections 2.1 and 2.2 constitute the IAE LBL calculational method. We have attempted to validate the method by computing fluxes and cooling rates for a number of clear-sky atmospheric profiles specified for the ICRCCM study [McClatchey et al., 1972] and for an observational measurement of clear-sky fluxes [Ackerman and Cox, 1982]. Table 5 summarizes the characteristics of these calculations.

Results of calculations of upward flux $\left(F_{\Delta \nu}^{+}(H)\right)$ and downward flux $\left(F_{\Delta \nu}^{-}(H)\right)$ for several profiles specified for the ICRCCM study are shown in Tables 6-8. In Table 6, fluxes for all levels between the surface and $100 \mathrm{~km}$ are displayed for five atmospheric profiles: tropical (TR), mid-latitude summer (MS) and winter (MW), and subarctic summer (SS) and winter ( $\mathrm{SW}$ ), with absorption from $\mathrm{H}_{2} \mathrm{O}, \mathrm{CO}_{2}$, and $\mathrm{O}_{3}$ all included. Table 7 gives results at the surface, tropopause, and top of the atmosphere for several more specialized cases; Table 8 displays some differences between these results and LBL calculations made by the GFDL [Schwarzkopf and Fels, this issue], GLA [Ridgway et al., this issue], and LMD [Luther, 1984] groups. We also have compared fluxes obtained with these techniques with observed measurements of clear-sky fluxes [Ackerman and Cox, 1982]. Results are displayed in Figure 7.
It is apparent from the results in Table 8 that the IAE calculations give discrepancies of several $\mathrm{W} / \mathrm{m}^{2}$ in certain cases (e.g., in the case when $\mathrm{H}_{2} \mathrm{O}$ (with continuum), $\mathrm{CO}_{2}$, and $\mathrm{O}_{3}$ are all included). In other cases, the discrepancy is small, as in the $\mathrm{CO}_{2}$-only calculations. Since the initial data for these calculations are essentially identical, the explanation of these differences must lie in the various LBL calculational techniques and the methods for accounting for atmospheric inhomogeneity. In some cases, such as the choice of absorption profile in distant wings of lines, the influence of LBL methods on the results is fairly evident. In other cases, such as the method for performing the angular integration, the differences are difficult to interpret.

To clarify these effects, we have performed a series of test calculations for the MS profile, in which a number of modifications have been made to the IAE technique given above. Results for the downward flux at the surface and at the tropopause are presented in Table 9. Flux values given as $F_{a}$ have been obtained using the accurate methods outlined above. Fluxes designated $F_{b}$ have been obtained with a 10 $\mathrm{cm}^{-1}$ cutoff in the line profile of all absorbers, and with the temperature dependence of $\alpha_{i}^{L}$ defined as $(296 / T)^{0.5}$. Fluxes denoted as $F_{c}$ have been computed using the diffusivity factor of 1.667 to account for the angular integration. Finally, the $F_{d}$ fluxes are obtained using homogeneous layers about $1 \mathrm{~km}$ wide to perform the vertical integrations of (12)-(13). In this case, the vertical interpolation of $\tau_{\nu}$ and associated functions remain as outlined in (9)-(10) (i.e., using the $\Delta Z_{j}$ interpolation grid).

It is apparent that the largest differences in the computed fluxes occur when the actual techniques accounting for temperature stratification [Trotsenko and Fomin, 1986, 1987]

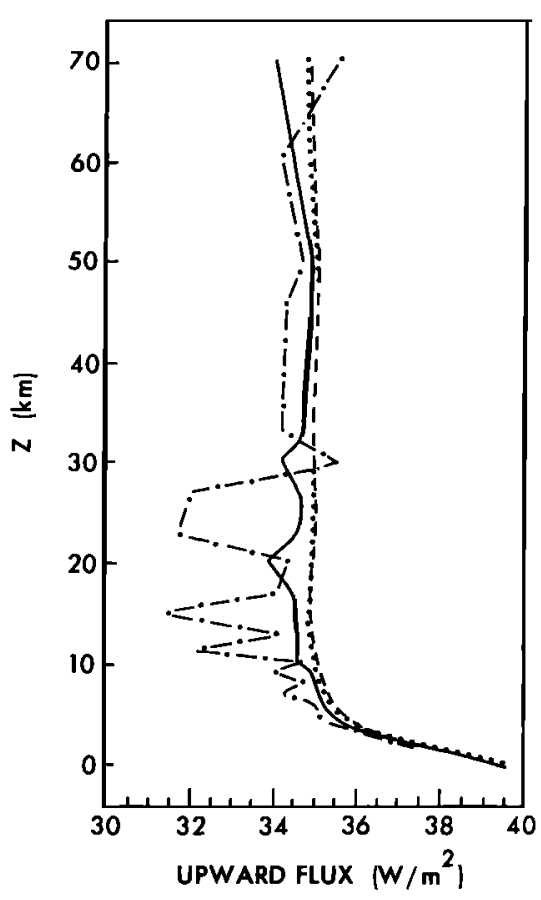

Fig. 6. Upward flux in the $800-900 \mathrm{~cm}^{-1}$ interval for the tropical profile, obtained with different $\varphi_{H}$ vertical interpolation grids. Gaseous absorbers are $\mathrm{H}_{2} \mathrm{O}$ (with continuum), $\mathrm{CO}_{2}$ (300 ppmv), and $\mathrm{O}_{3}$. Shown are the results using the $\Delta Z_{\nu}$ grid with 70 vertical levels (dot-dash curve), 130 vertical levels (solid curve), 260 vertical levels (dashed curve), and 520 vertical levels (dotted curve). 
TABLE 5. Summary of the Parameterizations and Data Bases Used for the LBL Calculations in Section 2.3

\begin{tabular}{|c|c|}
\hline Parameter & Description \\
\hline Absorption components & $\begin{array}{l}\mathrm{H}_{2} \mathrm{O}, \mathrm{CO}_{2}, \mathrm{O}_{3}\left(0-2600 \mathrm{~cm}^{-1}\right) ; \\
\quad \mathrm{H}_{2} \mathrm{O} \text { continuum }\left(400-1250 \mathrm{~cm}^{-1}\right)\end{array}$ \\
\hline Spectral range & $0-2600 \mathrm{~cm}^{-1}$ \\
\hline Spectroscopic data base & AFGL catalog, 1980 version \\
\hline $\begin{array}{l}\text { Temperature dependence of the Lorentz } \\
\text { half width }\end{array}$ & $\begin{array}{l}\text { 15- } \mu \mathrm{m} \mathrm{CO}_{2} \text { band }(296 / T)^{0.75} \\
\text { other gases }(296 / T)^{0.5}\end{array}$ \\
\hline Line cutoff criteria & $\begin{array}{l}\text { Determined by } \varepsilon \text { criterion (see Table } 4 \text { ); } \\
\text { maximum } 10 \mathrm{~cm}^{-1} \text { except in } 15-\mu \mathrm{m} \\
\mathrm{CO}_{2} \text { band, where Benedict correction is used }\end{array}$ \\
\hline Angular integration & Exponential integrals employed \\
\hline Vertical quadrature method & Linear interpolation using several altitude grids \\
\hline Minimum spectral resolution of available data & $5 \mathrm{~cm}^{-1}$ \\
\hline
\end{tabular}

are not employed $\left(F_{d}\right)$. The most substantial discrepancies occur in regions with strong absorption and high temperature gradients because in these areas the altitude dependence of the atmospheric emission properties is strongly perturbed. At the same time, in regions where temperature varies weakly with altitude (e.g., the tropopause), the use of the stratification technique has little effect on the result. Similarly, when the absorber amount is low, the stratification technique does not affect the flux results. This may be ascertained by comparison of the fluxes computed for the mid-latitude summer atmosphere for individual gases with results of other LBL calculations, given in Tables 7-8.

Calculations producing the $F_{b}$ fluxes have been designed to test the improvement in the $15-\mu \mathrm{m} \mathrm{CO}_{2}$ band results owing to the use of a different temperature dependence for $\alpha_{i}^{L}$ and a more sophisticated accounting of the contribution of distant wings to the line absorption. Table 9 indicates that the surface downward flux result is almost unaffected by use of the simpler methods. At the tropopause, the effect is rather larger, but the absolute difference between $F_{a}$ and $F_{b}$ is under $1 \mathrm{~W} / \mathrm{m}^{2}$. The most likely reason for the lack of effect in the troposphere is that the high absorption coefficients resulting from high absorber concentrations and broad line widths make any additional contributions from wings of distant lines unnoticeable. At the same time, at the tropopause, where the absorber amounts are less and line widths also reduced, the effects of distant lines are more pronounced.

TABLE 6. Frequency-Integrated Fluxes $\left(0-2600 \mathrm{~cm}^{-1}\right)$ for Clear-Sky IAE LBL Calculations

\begin{tabular}{|c|c|c|c|c|c|c|c|c|c|c|}
\hline \multirow{2}{*}{$\begin{array}{l}\text { Level, } \\
\text { km }\end{array}$} & \multicolumn{2}{|c|}{ Tropical } & \multicolumn{2}{|c|}{$\begin{array}{l}\text { Mid-Latitude } \\
\text { Summer }\end{array}$} & \multicolumn{2}{|c|}{$\begin{array}{l}\text { Subarctic } \\
\text { Summer }\end{array}$} & \multicolumn{2}{|c|}{$\begin{array}{l}\text { Mid-Latitude } \\
\text { Winter }\end{array}$} & \multicolumn{2}{|c|}{$\begin{array}{c}\text { Subarctic } \\
\text { Winter }\end{array}$} \\
\hline & $F^{+}$ & $F^{-}$ & $F^{+}$ & $F^{-}$ & $F^{+}$ & $F^{-}$ & $F^{+}$ & $F^{-}$ & $F^{+}$ & $F^{-}$ \\
\hline 0 & 458.5 & 397.8 & 423.0 & 348.9 & 384.3 & 298.2 & 311.0 & 218.8 & 247.7 & 166.7 \\
\hline 1 & 436.0 & 340.4 & 409.8 & 303.9 & 370.3 & 260.7 & 304.0 & 196.2 & 250.6 & 159.4 \\
\hline 2 & 412.2 & 288.7 & 393.1 & 261.5 & 353.2 & 225.5 & 296.3 & 173.1 & 247.0 & 142.0 \\
\hline 3 & 396.6 & 245.1 & 375.6 & 220.0 & 339.1 & 194.0 & 288.9 & 149.0 & 242.0 & 122.8 \\
\hline 4 & 378.3 & 202.9 & 360.2 & 184.0 & 327.1 & 164.0 & 279.2 & 122.9 & 235.3 & 100.8 \\
\hline 5 & 361.7 & 166.6 & 347.1 & 152.9 & 315.5 & 134.9 & 270.3 & 99.4 & 227.7 & 78.5 \\
\hline 6 & 348.9 & 136.1 & 335.9 & 126.8 & 304.2 & 108.0 & 262.8 & 78.6 & 221.0 & 59.5 \\
\hline 7 & 337.4 & 108.5 & 326.2 & 103.6 & 294.6 & 84.5 & 256.6 & 60.8 & 215.9 & 44.7 \\
\hline 8 & 327.7 & 84.9 & 317.1 & 82.6 & 286.8 & 64.0 & 251.6 & 46.5 & 211.9 & 35.7 \\
\hline 9 & 320.4 & 64.8 & 310.0 & 65.0 & 280.8 & 47.5 & 247.6 & 36.3 & 209.3 & 30.8 \\
\hline 10 & 314.3 & 47.0 & 303.6 & 48.7 & 276.0 & 37.4 & 244.2 & 29.5 & 208.0 & 27.5 \\
\hline 11 & 309.4 & 33.3 & 298.8 & 34.8 & 273.8 & 31.9 & 242.3 & 25.8 & 207.0 & 24.6 \\
\hline 13 & 302.8 & 18.2 & 291.8 & 20.8 & 271.4 & 24.7 & 240.0 & 20.4 & 205.6 & 19.8 \\
\hline 15 & 298.5 & 13.0 & 289.1 & 17.9 & 269.8 & 21.0 & 238.4 & 16.8 & 204.6 & 16.3 \\
\hline 17 & 295.2 & 11.0 & 287.4 & 15.5 & 268.4 & 17.9 & 237.1 & 14.0 & 203.7 & 13.3 \\
\hline 20 & 294.0 & 10.4 & 285.7 & 12.7 & 267.1 & 13.9 & 235.8 & 10.5 & 202.6 & 9.6 \\
\hline 23 & 293.6 & 9.2 & 285.0 & 10.3 & 266.3 & 10.8 & 235.0 & 7.7 & 201.9 & 6.8 \\
\hline 27 & 293.3 & 7.1 & 285.0 & 7.8 & 266.4 & 8.0 & 234.6 & 5.2 & 201.5 & 4.5 \\
\hline 30 & 293.6 & 5.7 & 285.4 & 6.2 & 266.7 & 6.4 & 234.5 & 4.0 & 201.6 & 3.4 \\
\hline 33 & 294.0 & 4.6 & 285.9 & 5.1 & 267.3 & 5.3 & 234.7 & 3.3 & 201.7 & 2.7 \\
\hline 37 & 294.7 & 3.5 & 286.6 & 3.9 & 268.1 & 4.2 & 235.2 & 2.6 & 202.0 & 2.1 \\
\hline 41 & 295.3 & 2.7 & 287.4 & 3.0 & 269.0 & 3.3 & 235.8 & 2.1 & 202.4 & 1.7 \\
\hline 45 & 295.9 & 2.0 & 288.1 & 2.3 & 269.7 & 2.5 & 236.4 & 1.7 & 202.8 & 1.4 \\
\hline 50 & 296.4 & 1.4 & 288.6 & 1.6 & 270.1 & 1.6 & 236.8 & 1.2 & 203.2 & 1.1 \\
\hline 60 & 295.4 & 0.5 & 287.6 & 0.5 & 269.1 & 0.5 & 236.4 & 0.5 & 203.2 & 0.5 \\
\hline 70 & 294.6 & 0.2 & 286.8 & 0.2 & 268.3 & 0.2 & 236.0 & 0.2 & 203.1 & 0.2 \\
\hline 100 & 294.0 & 0.0 & 286.6 & 0.0 & 268.1 & 0.0 & 235.9 & 0.0 & 202.6 & 0.0 \\
\hline
\end{tabular}

The gaseous absorbers include $\mathrm{H}_{2} \mathrm{O}$ (with continuum), $\mathrm{CO}_{2}(300 \mathrm{ppmv})$, and $\mathrm{O}_{3}$. Upward $\left(F^{+}\right)$and downward $\left(F^{-}\right)$fluxes are shown for the five standard atmospheric profiles at atmospheric levels (given in kilometers). Fluxes are in $\mathrm{W} / \mathrm{m}^{2}$. 
TABLE 7. Frequency-Integrated Fluxes $\left(100-2600 \mathrm{~cm}^{-1}\right)$ for the MS Profile at the Surface, Tropopause, and Top of the Atmosphere Obtained Using the IAE Method

\begin{tabular}{|c|c|c|c|c|c|c|c|c|c|c|c|c|}
\hline \multirow{2}{*}{$\begin{array}{l}\text { Level, } \\
\text { km }\end{array}$} & \multicolumn{2}{|c|}{$\begin{array}{l}\mathrm{H}_{2} \mathrm{O} \text { Lines } \\
\text { Only }\end{array}$} & \multicolumn{2}{|c|}{$\begin{array}{l}\mathrm{CO}_{2} \text { Lines } \\
\text { Only }\end{array}$} & \multicolumn{2}{|c|}{$\begin{array}{l}\mathrm{O}_{3} \text { Lines } \\
\text { Only }\end{array}$} & \multicolumn{2}{|c|}{$\begin{array}{c}\mathrm{H}_{2} \mathrm{O}+\mathrm{CO}_{2}(600 \text { ppmv })+ \\
\mathrm{O}_{3}+\mathrm{H}_{2} \mathrm{O} \text { Continuum }\end{array}$} & \multicolumn{2}{|c|}{$\begin{array}{c}\mathrm{H}_{2} \mathrm{O} \text { Lines Only, } \\
0.75 \times\left(\text { Standard } \mathrm{H}_{2} \mathrm{O}\right. \\
\text { Concentration })\end{array}$} & \multicolumn{2}{|c|}{$\begin{array}{c}\mathrm{H}_{2} \mathrm{O} \text { Lines Only, } \\
1.25 \times\left(\text { Standard } \mathrm{H}_{2} \mathrm{O}\right. \\
\text { Concentration })\end{array}$} \\
\hline & $F^{+}$ & $F^{-}$ & $F^{+}$ & $F^{-}$ & $F^{+}$ & $F^{-}$ & $F^{+}$ & $F^{-}$ & $F^{+}$ & $F^{-}$ & $F^{+}$ & $F^{-}$ \\
\hline 0 & 420.9 & 265.8 & 420.9 & 76.3 & 420.9 & 6.0 & 423.0 & 351.2 & 423.0 & 259.3 & 423.0 & 274.5 \\
\hline 13 & 333.2 & 5.8 & 380.3 & 12.2 & 417.0 & 3.1 & 287.5 & 22.5 & 339.6 & 5.4 & 330.8 & 6.9 \\
\hline 100 & 332.7 & 0.0 & 380.9 & 0.0 & 409.3 & 0.0 & 283.3 & 0.0 & 339.1 & 0.0 & 330.4 & 0.0 \\
\hline
\end{tabular}

Fluxes are in $\mathrm{W} / \mathrm{m}^{2}$.

Deviations from the "accurate" fluxes $F_{a}$ owing to the use of the diffusivity factor are insignificant as compared to the temperature stratification effects. At each atmospheric level, these deviations are less than the errors permitted in obtaining the $F_{a}$ fluxes $\left(0.5 \mathrm{~W} / \mathrm{m}^{2}\right)$.

Wideband and narrow-band random models often employ the approximations used in calculating $F_{b}, F_{c}$, and $F_{d}$. In section 3 , we will consider in further detail the effect of these approximations on the accuracy of such random models.

Cooling rates may be derived from the flux results by use of the following expression:

$$
Q=\frac{1}{\left(\rho C_{P}\right)} \frac{\partial F_{\text {net }}}{\partial Z}
$$

where $\rho$ and $C_{P}$ are the density and the heat capacity at constant pressure for moist air, respectively, $F_{\text {net }}$ is the net flux, and $Q$ the cooling rate. The differentiation in (24) is performed by means of a parabolic interpolation of $F_{\text {net }}$. Diagnostic calculations for specified atmospheric profiles and specified net flux values indicate that this procedure yields errors no larger than $0.1 \mathrm{~K} / \mathrm{d}$ in the troposphere and above the region of the tropopause. Near the tropopause, it is difficult to estimate the errors, owing to the strong altitude dependence of $F_{\text {net }}$ and the lack of specified flux calculation levels in this region.

In Figure 8 we display cooling rate calculations for the mid-latitude summer atmosphere with $\mathrm{H}_{2} \mathrm{O}$ (without continuum), $\mathrm{CO}_{2}$, and $\mathrm{O}_{3}$ as absorbers. For purposes of comparison, corresponding results from the GFDL and LMD groups (given by Luther [1984]) are also shown. Substantial agreement is shown between the present results and those of the other groups, except above $25 \mathrm{~km}$. The discrepancies

TABLE 8. Differences Between the Present (IAE) Results for Frequency-Integrated Fluxes and Those of Other LBL Calculations

\begin{tabular}{|c|c|c|c|c|c|c|c|}
\hline \multirow[b]{2}{*}{ Case } & \multirow{2}{*}{$\begin{array}{c}\text { Level, } \\
\text { km }\end{array}$} & \multicolumn{2}{|c|}{ IAE-GFDL } & \multicolumn{2}{|c|}{ IAE-GLA } & \multicolumn{2}{|c|}{ IAE-LMD } \\
\hline & & $\mathrm{F}^{+}$ & $F^{-}$ & $F^{+}$ & $F^{-}$ & $\mathrm{F}^{+}$ & $F^{-}$ \\
\hline TR & $\begin{array}{r}0 \\
17 \\
100\end{array}$ & $\begin{array}{r}2.1 \\
-4.0 \\
-4.3\end{array}$ & $\begin{array}{r}7.9 \\
-0.1\end{array}$ & & & $\begin{array}{r}2.1 \\
-3.3 \\
-2.8\end{array}$ & $\begin{array}{r}8.3 \\
-0.5\end{array}$ \\
\hline MS & $\begin{array}{r}0 \\
13 \\
100\end{array}$ & $\begin{array}{l}-0.6 \\
-3.4 \\
-3.7\end{array}$ & $\begin{array}{r}5.6 \\
-0.5\end{array}$ & $\begin{array}{l}-0.5 \\
-3.5 \\
-3.9\end{array}$ & $\begin{array}{l}5.8 \\
0.0\end{array}$ & $\begin{array}{r}2.0 \\
-0.2 \\
-1.5\end{array}$ & $\begin{array}{l}8.7 \\
0.9\end{array}$ \\
\hline MW & $\begin{array}{r}0 \\
13 \\
100\end{array}$ & $\begin{array}{r}0.6 \\
-0.7 \\
-0.7\end{array}$ & $\begin{array}{r}3.4 \\
-0.7\end{array}$ & & & $\begin{array}{l}1.8 \\
3.5 \\
0.7\end{array}$ & $\begin{array}{l}8.3 \\
5.7\end{array}$ \\
\hline SS & $\begin{array}{r}0 \\
13 \\
100\end{array}$ & $\begin{array}{r}1.3 \\
-1.4 \\
-1.9\end{array}$ & $\begin{array}{r}5.6 \\
-0.5\end{array}$ & & & $\begin{array}{r}2.0 \\
0.5 \\
-1.3\end{array}$ & $\begin{array}{r}10.9 \\
3.1\end{array}$ \\
\hline SW & $\begin{array}{r}0 \\
13 \\
100\end{array}$ & $\begin{array}{r}0.3 \\
-0.1 \\
-0.4\end{array}$ & $\begin{array}{r}2.3 \\
-0.5\end{array}$ & $\begin{array}{r}0.0 \\
-0.5 \\
-0.8\end{array}$ & $\begin{array}{l}2.1 \\
0.3\end{array}$ & $\begin{array}{l}1.8 \\
0.4 \\
1.3\end{array}$ & $\begin{array}{r}4.3 \\
-1.8\end{array}$ \\
\hline $\mathrm{H}_{2} \mathrm{O}$ lines only & $\begin{array}{r}0 \\
13 \\
100\end{array}$ & $\begin{array}{l}-2.7 \\
-3.4 \\
-3.6\end{array}$ & $\begin{array}{l}-1.0 \\
-0.9\end{array}$ & $\begin{array}{l}-2.6 \\
-3.4 \\
-3.8\end{array}$ & $\begin{array}{l}-1.3 \\
-0.5\end{array}$ & $\begin{array}{r}-0.1 \\
2.2 \\
3.2\end{array}$ & $\begin{array}{l}-1.5 \\
-0.5\end{array}$ \\
\hline $\mathrm{CO}_{2}$ lines only & $\begin{array}{r}0 \\
13 \\
100\end{array}$ & $\begin{array}{l}-2.7 \\
-2.9 \\
-2.8\end{array}$ & $\begin{array}{l}0.0 \\
0.1\end{array}$ & $\begin{array}{l}-2.6 \\
-2.8 \\
-2.7\end{array}$ & $\begin{array}{r}-0.2 \\
0.1\end{array}$ & $\begin{array}{r}-0.1 \\
0.1 \\
0.0\end{array}$ & $\begin{array}{r}-0.1 \\
0.4\end{array}$ \\
\hline $\mathrm{O}_{3}$ lines only & $\begin{array}{r}0 \\
13 \\
100\end{array}$ & $\begin{array}{l}-2.7 \\
-2.4 \\
-2.8\end{array}$ & $\begin{array}{r}-0.2 \\
0.1\end{array}$ & $\begin{array}{l}-2.6 \\
-2.6 \\
-2.7\end{array}$ & $\begin{array}{l}0.0 \\
0.0\end{array}$ & $\begin{array}{r}-0.1 \\
0.6 \\
-2.3\end{array}$ & $\begin{array}{l}1.0 \\
1.1\end{array}$ \\
\hline $\begin{array}{l}\mathrm{MS} \\
\quad\left(\mathrm{CO}_{2}=\right. \\
\quad 600 \mathrm{ppmv})\end{array}$ & $\begin{array}{r}0 \\
13 \\
100\end{array}$ & $\begin{array}{r}1.7 \\
-2.7 \\
-2.7\end{array}$ & $\begin{array}{r}7.1 \\
-0.5\end{array}$ & $\begin{array}{l}-0.5 \\
-3.8 \\
-4.2\end{array}$ & $\begin{array}{l}6.3 \\
0.0\end{array}$ & $\begin{array}{r}2.0 \\
-0.6 \\
-1.8\end{array}$ & $\begin{array}{l}9.0 \\
0.9\end{array}$ \\
\hline
\end{tabular}

The fluxes are in $\mathrm{W} / \mathrm{m}^{2}$ and are given at the surface, at the tropopause, and at the top of the atmosphere. The $\mathrm{CO}_{2}=600 \mathrm{ppmv}$ case also includes the gaseous absorbers $\mathrm{H}_{2} \mathrm{O}$ (with continuum) and $\mathrm{O}_{3}$. 


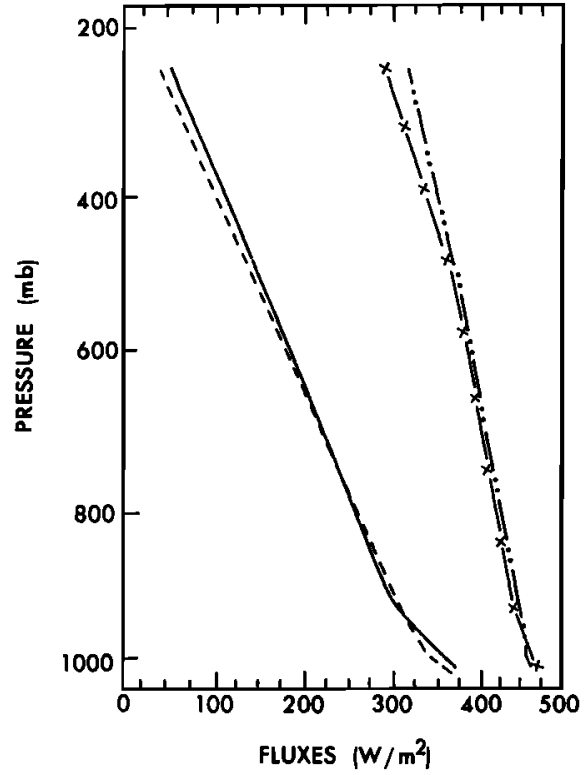

Fig. 7. Calculated and measured frequency integrated longwave fluxes. The frequency interval is $0-2600 \mathrm{~cm}^{-1}$; gaseous absorbers are $\mathrm{H}_{2} \mathrm{O}$ (with continuum), $\mathrm{CO}_{2}$, and $\mathrm{O}_{3}$. Downward fluxes are shown on the left of the figure, upward fluxes on the right. Solid lines are used for calculated fluxes using the IAE method; dot-dashed lines for measured fluxes from Ackerman and Cox [1982].

above $25 \mathrm{~km}$ are too large to be explained by errors in the net flux differentiation procedure; the cause of these differences is presently under investigation.

\section{Band Model Calculations}

\subsection{Development of the Wideband Model}

A frequently employed practical solution to the problem of computing longwave fluxes and flux divergences is to consider radiation in spectral bands of finite width, for which transmission functions may be determined in various ways. One of the first papers using this method was that of Rodgers and Walshaw [1966]; the approach was further developed by Ellingson and Gille [1978]. In this paper, we adopt a similar approach.

For a plane-parallel atmosphere in local thermodynamic equilibrium and with the effects of scattering neglected, the upward $F_{\Delta \nu}^{+}(H)$ and downward $F_{\Delta \nu}^{-}(H)$ longwave radiative fluxes in the spectral interval $\Delta \nu$ at the atmosphere level $H$ are calculated using formulas similar to those in Rodgers and Walshaw:

TABLE 9. Frequency-Integrated Downward Fluxes (100-2600 $\mathrm{cm}^{-1}$ ) for the MS Profile Calculated Using Different Model Approximations

\begin{tabular}{rrrrr}
\hline $\begin{array}{c}\text { Level, } \\
\mathrm{km}\end{array}$ & $F_{a}$ & $F_{b}$ & $F_{c}$ & \multicolumn{1}{c}{$\boldsymbol{F}_{d}$} \\
\hline 0 & 346.8 & 346.4 & 347.3 & 343.0 \\
13 & 20.4 & 19.7 & 19.8 & 19.9 \\
\hline
\end{tabular}

The gaseous absorbers include $\mathrm{H}_{2} \mathrm{O}$ (with continuum), $\mathrm{CO}_{2}(300$ ppmv), and $\mathrm{O}_{3} . \mathrm{F}_{a}$ fluxes are obtained using the methods of sections 2.1 and $2.2 ; F_{b}, F_{c}$, and $F_{d}$ fluxes are obtained using approximations given in section 2.3 . Fluxes are in $\mathrm{W} / \mathrm{m}^{2}$.

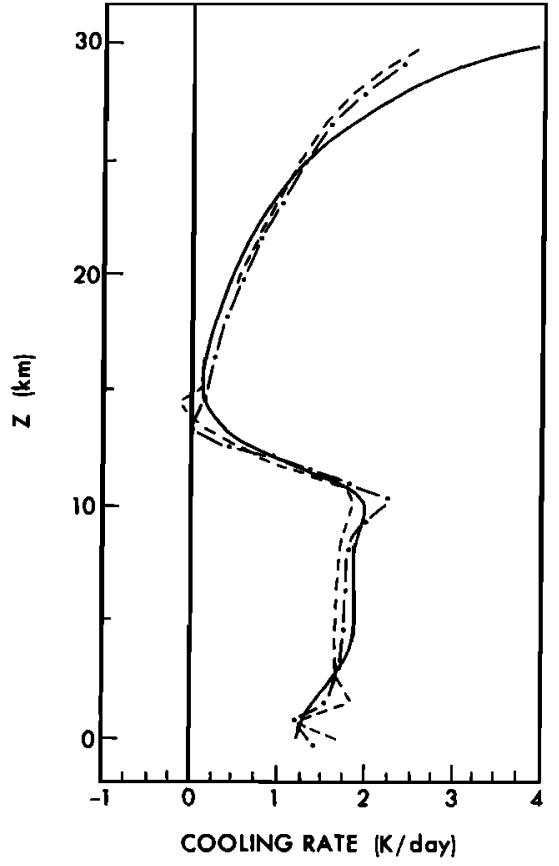

Fig. 8. Cooling rates obtained from the LBL calculations for the mid-latitude summer atmosphere. Gaseous absorbers are $\mathrm{H}_{2} \mathrm{O}$ (without continuum), $\mathrm{CO}_{2}$, and $\mathrm{O}_{3}$. Shown are the results from the present calculation (solid curve), from the LMD group (dashed curve), and from the GFDL group (dot-dashed curve).

$$
\begin{aligned}
& F_{\Delta \nu}^{+}(H)=B_{\nu}(H)-\int_{0}^{H} P_{\Delta \nu}^{f}(H, Z) \frac{d}{d Z} B(Z) d Z \\
& F_{\Delta \nu}^{-}(H)=B_{\nu}(H) P_{\Delta \nu}^{f}\left(H, Z_{N}\right)+B_{\nu}(H) \\
&+\int_{H}^{Z_{N}} P_{\Delta \nu}^{f}(H, Z) \frac{d}{d Z} B(Z) d Z
\end{aligned}
$$

where $P_{\Delta \nu}^{f}(H, Z)$ is the transmission function over the spectral interval, $B_{\nu}(Z)$ the Planck function in the spectral interval, with $\nu$ the middle of the interval, and $Z_{N}$ the effective top boundary of the atmosphere.

The initial application of these relations was the construction of a narrow-band model (NBM) with 140 spectral intervals (each $20-30 \mathrm{~cm}^{-1}$ wide) over the $0-2960 \mathrm{~cm}^{-1}$ range. The minor gaseous constituents (MGC) of the atmosphere incorporated in the model included $\mathrm{H}_{2} \mathrm{O}, \mathrm{CO}_{2}, \mathrm{O}_{3}$, $\mathrm{N}_{2} \mathrm{O}, \mathrm{CH}_{4}, \mathrm{NH}_{3}, \mathrm{HNO}_{3}, \mathrm{CF}_{2} \mathrm{Cl}_{2}$, and $\mathrm{CFCl}_{3}$ (chlorofluorocarbons), $\mathrm{CO}$ and NO. Different approximations were used to calculate the transmission functions for each gas. For $\mathrm{H}_{2} \mathrm{O}, \mathrm{O}_{3}, \mathrm{CH}_{4}, \mathrm{CO}, \mathrm{N}_{2} \mathrm{O}, \mathrm{CF}_{2} \mathrm{Cl}_{2}$, and $\mathrm{CFCl}_{3}$, the statistical model given by Goody [1964] and Rodgers and Walshaw [1966] has been used with band coefficients computed using data on the fine-structure parameters of the absorption bands from McClatchey et al. [1973] and (for the chlorofluorocarbons) from Goldman et al. [1976a, b]. For $\mathrm{CO}_{2}, \mathrm{NH}_{3}, \mathrm{NO}$, and $\mathrm{HNO}_{3}$, empirical formulas from Roberts et al. [1976], Goody [1964], Moskalenko [1969, 1972], Moskalenko et al. [1972], Moskalenko and Mirumiantz [1970], Minis and Cox [1976], and Smith [1969] were employed. The continuum absorption of $\mathrm{H}_{2} \mathrm{O}$ is included using the data of Roberts et al. [1976].

The statistical model assumes that spectral lines have a 
TABLE 10. Contributions of Gaseous Absorbers to the Downward Longwave Flux at the Surface $\left(\Delta F^{-}(0)\right)$ and to the Outgoing Longwave Flux $\left(\Delta F^{+}\left(Z_{N}\right)\right)$ for Three Atmospheric Profiles

\begin{tabular}{lrrrrrrr}
\hline & $\mathrm{H}_{2} \mathrm{O}$ & $\mathrm{CO}_{2}$ & \multicolumn{8}{c}{$\mathrm{O}_{3}$} & $\mathrm{~N}_{2} \mathrm{O}$ & $\mathrm{CFC}$ & $\mathrm{NH}_{3}$ & $\mathrm{HNO}_{3}$ \\
\hline \multicolumn{7}{c}{ Mid-Latitude } & Summer \\
$\Delta F^{-}(0)$ & 239.0 & 8.8 & 3.5 & 1.8 & 1.6 & 0.19 & 0.16 \\
$\Delta F^{+}\left(Z_{N}\right)$ & -80.9 & -31.6 & -11.1 & -4.8 & -1.8 & -0.22 & -0.18 \\
\multicolumn{7}{c}{ Tropical } \\
$\Delta F^{-}(0)$ & 282.4 & 3.2 & 2.1 & 1.5 & 1.1 \\
$\Delta F^{+}\left(Z_{N}\right)$ & -99.4 & -34.6 & -9.9 & -5.1 & -2.0 & \\
\multicolumn{7}{c}{ Subarctic Winter } \\
$\Delta F^{-}(0)$ & 113.8 & 34.0 & 3.5 & 3.4 & 1.7 & \\
$\Delta F^{+}\left(Z_{N}\right)$ & -23.9 & -18.0 & -5.8 & -2.6 & -0.8 \\
\hline
\end{tabular}

Computations use the narrow-band model described in section 3.1. Fluxes are in $\mathrm{W} / \mathrm{m}^{2}$. The influence of changes in CFC, $\mathrm{NH}_{3}$, and $\mathrm{HNO}_{3}$ amounts is evaluated using the removal of 20 times the present CFC concentration, and of double the present $\mathrm{NH}_{3}$ and $\mathrm{HNO}_{3}$ amounts.

Lorentz line shape. The transmission functions for the absorbing gases are then corrected for Doppler broadening using the method of Ellingson and Gille [1978]. A twoparameter Curtis-Godson approximation is used to account for inhomogeneous optical paths, but the dependence of line intensities and half widths on temperature was not included. The angular integrations in the flux calculations were performed using the diffusivity factor 1.667. Transmissivities for several gaseous absorbers were obtained by multiplication of the transmission function for each absorber [Goody, 1964].

Longwave fluxes computed using the above algorithm were obtained for the TR, MS, MW, SS, and SW profiles. In order to assess the contribution of each MGC to the final longwave radiation flux, we have computed fluxes with all constituents present and compared these results to those from calculations in which the constituent under examination in excluded. As an example, Table 10 displays the influence of individual MGC on the downward flux at the surface $\left(F^{-}(0)\right)$ and the upward flux at the top of the atmosphere $\left(F^{+}\left(Z_{N}\right)\right)$. The results enable us to subdivide the gases under consideration into three groups. The first group comprises $\mathrm{H}_{2} \mathrm{O}, \mathrm{CO}_{2}, \mathrm{O}_{3}, \mathrm{~N}_{2} \mathrm{O}$, and $\mathrm{CH}_{4}$, which must be included because of their current concentrations. The second group includes $\mathrm{CF}_{2} \mathrm{Cl}_{2}$ and $\mathrm{CFCl}_{3}$, which are important due to the predicted increase in their concentrations in the future. Finally, the third group includes $\mathrm{NH}_{3}, \mathrm{HNO}_{3}$, $\mathrm{NO}$, and $\mathrm{CO}$, which are insignificant at present and future concentrations.

The results of these tests have been used to develop a simplified wideband radiative model [Rozanov et al., 1981], designated as the MGO-LSU model. The major change is a considerable reduction of the number of spectral intervals and the exclusion of the gaseous constituents in the third group given above. The determination of the spectral intervals takes into account the structure of the absorption bands and the importance of individual intervals in the flux computation. In regions of strong absorption, narrower frequency bands are used; wider frequency bands are applied in regions of weak absorption. The final version contains 17 spectral intervals. The absorption of $\mathrm{H}_{2} \mathrm{O}, \mathrm{CO}_{2}, \mathrm{O}_{3}, \mathrm{~N}_{2} \mathrm{O}$, and $\mathrm{CH}_{4}$ is evaluated using the statistical model outlined above; details of the model parameters and of the spectral intervals are presented by Rozanov et al. [1981]. The transmission functions of the chlorofluorocarbons are calculated assuming weak absorption [Goody, 1964] with band intensities taken from Pugh and Rao [1976].

\subsection{Validation of the Wideband (MGO-LSU) Model}

Calculations using the MGO-LSU model have been compared with IAE results for the TR, MS, and SW atmospheric profiles. Figures $9 a-9 c$ shows cooling rates for these profiles using the two approaches.

Analysis of the results in the stratosphere reveals good agreement (within 3-5\%) up to $35 \mathrm{~km}$ for all profiles. The MGO-LSU model considerably underestimates cooling rates in the upper stratosphere. This effect is probably due to the effects of Doppler line broadening, which becomes impor$\operatorname{tant}$ in layers above $30 \mathrm{~km}$. It is likely that the method we employ to incorporate these effects [Ellingson and Gille, 1968] underestimates optical thicknesses above $30 \mathrm{~km}$, and thus yields cooling rates lower than the LBL results in this region. (a)

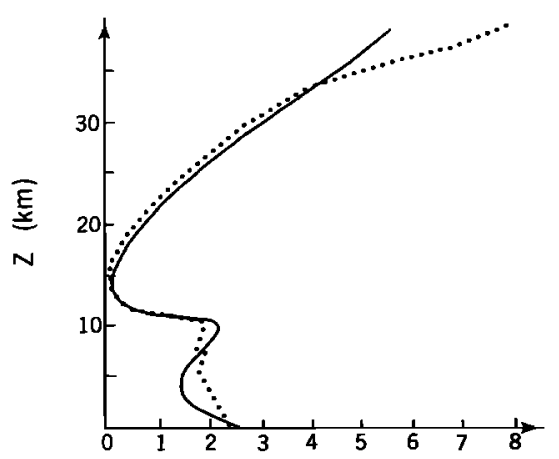

(b)

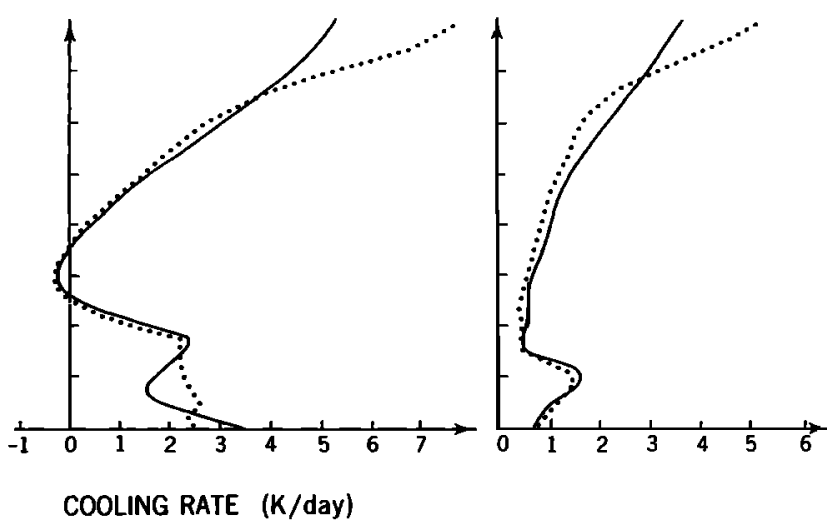

Fig. 9. Cooling rates obtained by the MGO-LSU and IAE models. Gaseous absorbers include $\mathrm{H}_{2} \mathrm{O}$ (with continuum), $\mathrm{CO}_{2}$, and $\mathrm{O}_{3}$. Curves are for (a) the MS profile, (b) the TR profile, and (c) the SW profile for the IAE results (dotted curves) and the MGO-LSU model results (solid curves). 

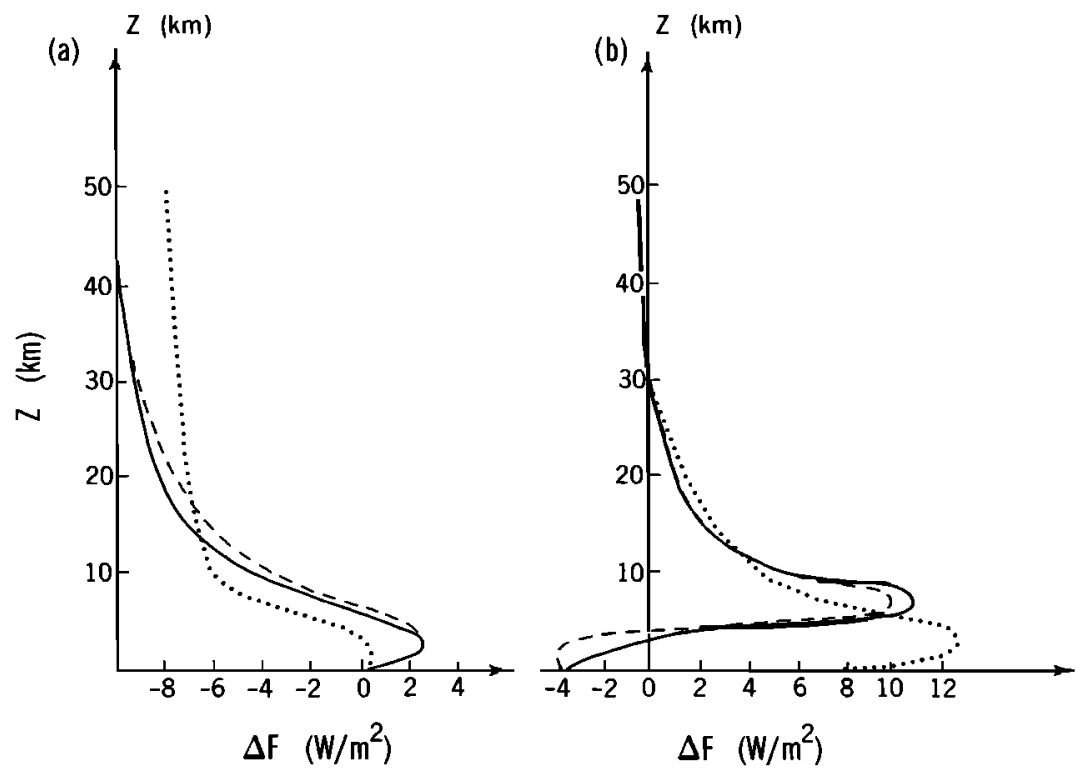

Fig. 10. Differences between fluxes obtained by the MGO-LSU model and the IAE calculation. Gaseous absorbers are as in Figure 9. The curves show $(a)$ upward fluxes and $(b)$ downward fluxes for the MS profile (solid curves), the TR profile (dashed curves), and the SW profile (dotted curves).

In the troposphere, good agreement is seen for the SW profile, whereas in the TR and MS results the MGO-LSU model technique yields a local cooling rate minimum at altitudes near $5 \mathrm{~km}$, while the IAE calculations give a fairly constant cooling rate from the surface to the tropopause. To explain these differences, we have obtained the differences in the frequency-integrated upward and downward fluxes computed by the IAE and MGO-LSU model approaches for the three atmospheric profiles. These differences are shown in Figure 10.

Inspection of this figure reveals an overestimation of the upward fluxes, and an underestimation of downward fluxes, in the region below 4-6 km for the TR and MS cases. Above this region, the MGO-LSU model underestimates upward fluxes; at about $30 \mathrm{~km}$, the differences between fluxes computed by the IAE and MGO-LSU methods become constant for both cases and reach $8-10 \mathrm{~W} / \mathrm{m}^{2}$ (or about $4 \%$ ). The downward fluxes are overestimated above the $5-\mathrm{km}$ region. The largest differences occur in the upper troposphere, where they approach $10-12 \mathrm{~W} / \mathrm{m}^{2}$ (about 15\%) for all three cases. The differences approach zero above $30 \mathrm{~km}$. The larger magnitude of the changes in downward fluxes (up to $8 \mathrm{~W} / \mathrm{m}^{2} / \mathrm{km}$ ) result in the decreased cooling rates observed in the TR and MS cases. For the SW model, upward fluxes are underestimated and downward fluxes overestimated at practically all altitudes. Since the magnitude of the changes in the downward and upward fluxes is similar, we observe rather smaller differences in the resulting cooling rates.

The likely cause of these discrepancies is the approximations used in the MGO-LSU model algorithm: the use of a diffusivity factor, the neglect of the temperature dependence of the transmission function, the parameterization of Doppler broadening, and the inherent errors in the statistical model. We have attempted to investigate these causes by performing a series of LBL calculations for the MS profile, with the above approximations introduced into the IAE LBL algorithm. When examining the influence of temperature dependence, absorption coefficients were determined at $T=$ $260 \mathrm{~K}$; when studying the effect of the diffusivity factor, the angular integration was replaced by the diffusivity factor 1.667; the influence of Doppler broadening was estimated by replacement of the line shapes used in the LBL calculations with the Lorentz line shape. The error due to the statistical model and the Curtis-Godson approximation has been determined by the difference between the MGO-LSU model fluxes and the IAE computations made using the Lorentz line shape, the diffusivity factor, and the temperatureindependent absorption coefficients.

Results of these calculations are presented in Figure $11 a$ (for upward fluxes) and $11 b$ (for downward fluxes). It is apparent that the use of the diffusivity factor and of the Lorentz line shape produces quite small errors. In fact, these approximations produce a negligible effect (less than 0.5 $\mathrm{W} / \mathrm{m}^{2}$ ) on the upward flux. Errors in the downward fluxes are never more than $1-2 \mathrm{~W} / \mathrm{m}^{2}$, with the largest error occurring in the lower troposphere in the case of the diffusivity factor effect, and in the middle and upper stratosphere in the case of Doppler broadening (as noted above).

The most significant differences are due to the neglect of the temperature dependence and to the use of the statistical model and the Curtis-Godson approximation. In the lower troposphere, the error connected with the temperature prevails, especially for the downward flux. At higher levels in the troposphere, the contributions of the two effects to the total error are approximately equal. From these calculations we estimate that a proper inclusion of the temperature dependence of the transmission function will eliminate most of the discrepancies between the IAE and MGO-LSU model calculations for the upward flux, and decrease the maximum difference in downward flux by almost a factor of 2 .

A second approach to validation of the MGO-LSU model is to compare its response to changes in model parameters with the corresponding responses of the IAE calculations. This comparison has been done in two ways: first, by 


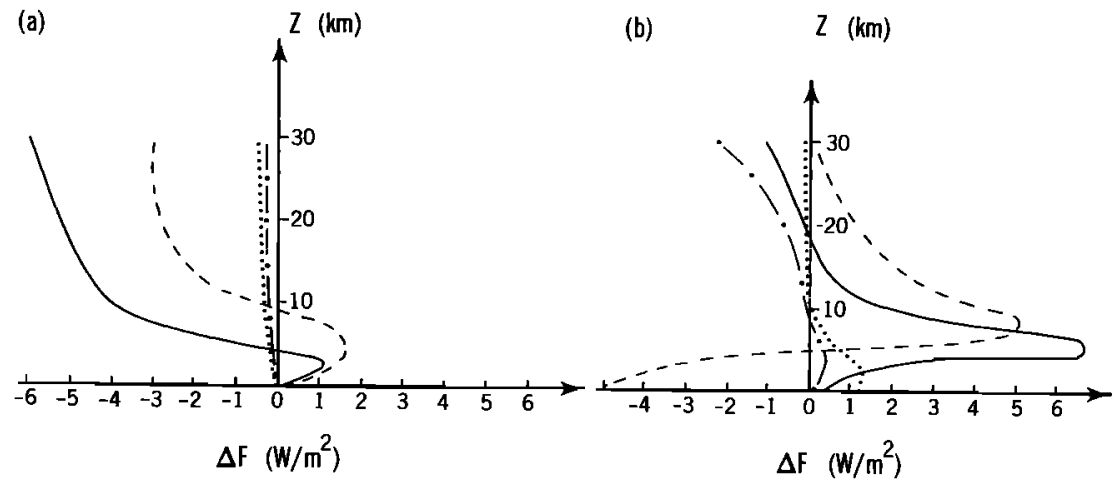

Fig. 11. Errors in upward and downward fluxes in the IAE calculations for the MS profile using approximate formulations. Absorbers are as in Figure 9. Curves show $(a)$ upward fluxes and $(b)$ downward fluxes with errors due to the statistical model and the Curtis-Godson approximation (solid curves), errors due to temperature dependence of transmissivities (dashed curves), errors due to the diffusivity factor (dotted curves), and errors due to exclusion of Doppler broadening (dot-dash curves).

comparing the changes in fluxes due to a doubling of the $\mathrm{CO}_{2}$ amount and, second, by comparing the deviations in fluxes owing to the transition from the MS profile to the TR and SW profiles.

Results of calculations comparing the response of the IAE and MGO-LSU model calculations (on the MS profile) to doubling of $\mathrm{CO}_{2}$ are presented in Figure 12. These curves indicate that in the troposphere, the MGO-LSU model reproduces the changes in the upward and downward fluxes computed by the IAE approach to within $0.3 \mathrm{~W} / \mathrm{m}^{2}$ (or about $8 \%$ ). At the top of the atmosphere, the discrepancies are somewhat larger, reaching $0.5 \mathrm{~W} / \mathrm{m}^{2}$ (or about $14 \%$ ).

The sensitivity of the IAE and MGO-LSU model flux calculations to variations in atmospheric profiles is displayed in Figure 13. In the stratosphere, the flux changes obtained by the IAE method are reproduced by the MGO-LSU model approach to about $1 \mathrm{~W} / \mathrm{m}^{2}$, or about $3 \%$. In the troposphere, the MGO-LSU model result considerably underestimates (by $3-5 \mathrm{~W} / \mathrm{m}^{2}$ or $10-14 \%$ ) the variations in downward flux.

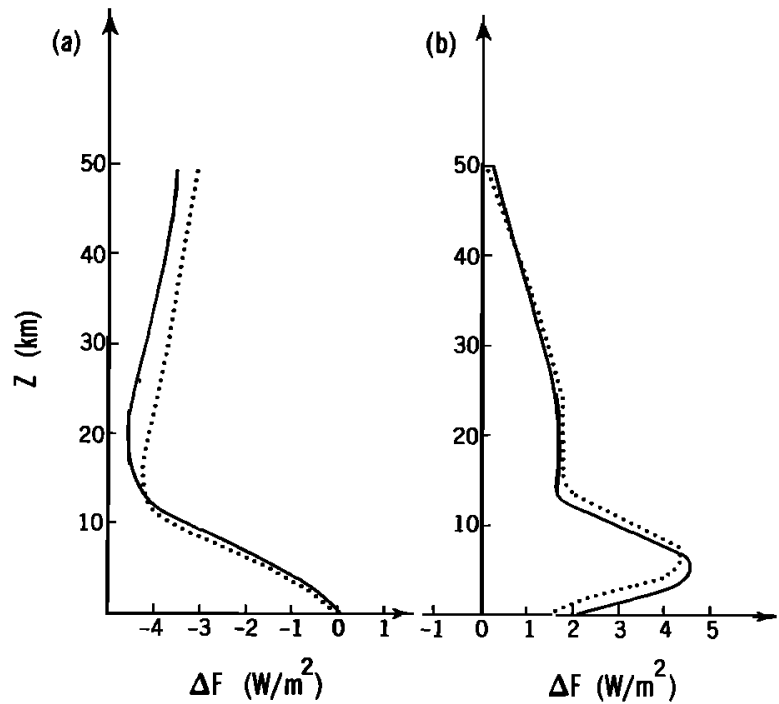

Fig. 12. Change in fluxes due to a doubling of $\mathrm{CO}_{2}$ in the MGO-LSU and IAE models. The solid lines are for the IAE calculation; the dotted lines for the MGO-LSU model for (a) upward fluxes and $(b)$ downward fluxes.
The upward flux variations are reproduced much better; the resulting overestimation is only $1-2 \mathrm{~W} / \mathrm{m}^{2}$, or $2-4 \%$.

\section{INTEGRAL TRANSMISSION FUNCTION}

The integral transmission function (ITF) for water vapor and carbon dioxide [Nijlisk et al., 1969] has been derived as a means for rapid computation of longwave fluxes and cooling rates. The approach uses formulas given by Davis and Viezee [1964] for computations in the $25-2150 \mathrm{~cm}^{-1}$ spectral interval, and tables from Wyatt et al. [1962] and Stull et al. [1963] for computations in the $2150-2975 \mathrm{~cm}^{-1}$ region. The "window region" $\left(800-1200 \mathrm{~cm}^{-1}\right)$ is excluded from the ITF and replaced by a calculation of $\mathrm{H}_{2} \mathrm{O}$ continuum absorption using the method of Roberts et al. [1976]

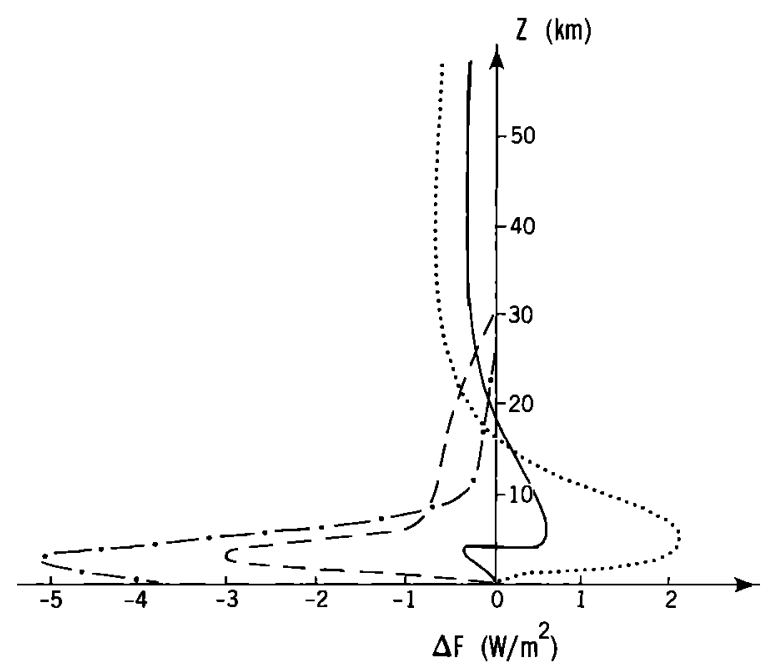

Fig. 13. Difference in the response of the IAE and MGO-LSU methods to a change in atmospheric profile. The solid curve gives the difference between the changes of the upward flux computed by the two models when the TR profile is replaced by the MS profile. The dashed curve gives the corresponding difference for downward fluxes. The dot-dash curve is similar to the solid curve, except that the results are for the replacement of the SW profile by the MS profile. The dotted curve is the corresponding difference for downward fluxes. A positive value implies overestimation by the wideband model of flux variations. 
TABLE 11. Differences Between Fluxes Computed by the Integral Transmission Function (ITF) and the IAE Method for Three Atmospheric Profiles

\begin{tabular}{|c|c|c|c|c|c|c|}
\hline \multirow{2}{*}{$\begin{array}{l}\text { Level, } \\
\text { km }\end{array}$} & \multicolumn{2}{|c|}{ Tropical } & \multicolumn{2}{|c|}{$\begin{array}{l}\text { Mid-Latitude } \\
\text { Summer }\end{array}$} & \multicolumn{2}{|c|}{$\begin{array}{c}\text { Subarctic } \\
\text { Winter }\end{array}$} \\
\hline & $\Delta F^{+}$ & $\Delta F^{-}$ & $\Delta F^{+}$ & $\Delta F^{-}$ & $\Delta F^{+}$ & $\Delta F^{-}$ \\
\hline 0 & 0 & 11 & 0 & 10 & 0 & 4 \\
\hline 3 & -3 & 6 & -2 & 9 & -1 & 3 \\
\hline 6 & 4 & 6 & -2 & 9 & -1 & 3 \\
\hline 9 & 10 & 5 & 11 & 5 & 2 & 2 \\
\hline 13 & 13 & 4 & 10 & 6 & 4 & 3 \\
\hline 15 & 13 & 3 & 11 & 9 & 4 & 3 \\
\hline 17 & 13 & 3 & 10 & 9 & 4 & 3 \\
\hline 20 & 14 & 4 & 11 & 8 & 3 & 4 \\
\hline
\end{tabular}

$\Delta F^{+}$is $F^{+}(\mathrm{ITF})-F^{+}(\mathrm{IAE})$, in $\mathrm{W} / \mathrm{m}^{2}$, for the upward flux. $\Delta F^{-}$ is the corresponding quantity for the downward flux. The calculation is performed at eight vertical levels.

[see Gorchakova and Feigelson, 1982]. Ozone absorption is included in the same manner as in the MGO-LSU model [Rozanov et al., 1981]. The temperature dependence of the ITF is not included in this calculation. The pressure dependence is introduced by defining the "reduced mass":

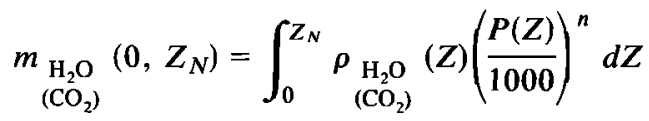

with $n=1$ for $\mathrm{H}_{2} \mathrm{O}$ and $\mathrm{CO}_{2} ; \rho(Z)$ is the density of the corresponding gas at altitude $Z$.

The accuracy of this approach has been evaluated by comparison with IAE calculations obtained using the methods of section 2. Table 11 presents the differences in upward $\left(\Delta F^{+}\right)$and downward $\left(\Delta F^{-}\right)$fluxes between the ITF and IAE results for the TR, MS, and SW profiles. Errors of up to $14 \mathrm{~W} / \mathrm{m}^{2}$ occur in the upper troposphere in the TR and MS cases. Cooling rates for the MS case $\left(\mathrm{H}_{2} \mathrm{O}\right.$ (without continuum) $+\mathrm{CO}_{2}+\mathrm{O}_{3}$ ), shown in Figure 14, indicate an underestimation of flux divergences in the ITF calculations, with errors in the middle troposphere amounting to about $0.25 \mathrm{~K} / \mathrm{d}$.

The sensitivity of the ITF to parameter changes has also been tested. Table 12 presents the differences in upward and downward fluxes for the IAE and ITF results when changing from the TR to the MS profile, and when changing from the MS profile to the SW profile. It is evident that the ITF sensitivity generally is similar to that of the IAE calculation. A similar conclusion may be made when IAE and ITF sensitivities to a doubling of $\mathrm{CO}_{2}$ are compared in an MS atmosphere. The changes in downward flux at the surface are $2.3 \mathrm{~W} / \mathrm{m}^{2}$ in the IAE calculations and $2.1 \mathrm{~W} / \mathrm{m}^{2}$ in the ITF results. The changes in upward flux at the top of the atmosphere are $3.3 \mathrm{~W} / \mathrm{m}^{2}$ for both models. The changes in flux divergences through the troposphere amount to -4.0 $\mathrm{W} / \mathrm{m}^{2}$ in both models. Further details on the ITF calculations are presented by Galtsev et al. [1987].

ITF calculations have been used to determine the parameter $\vartheta$ [see Mokhov, 1981; Gorchakova and Feigelson, 1984], often used in climate theory:

$$
\vartheta=\frac{\partial F^{+}\left(Z_{N}\right)}{\partial \ln \left(m_{\mathrm{CO}_{2}}\right)}
$$

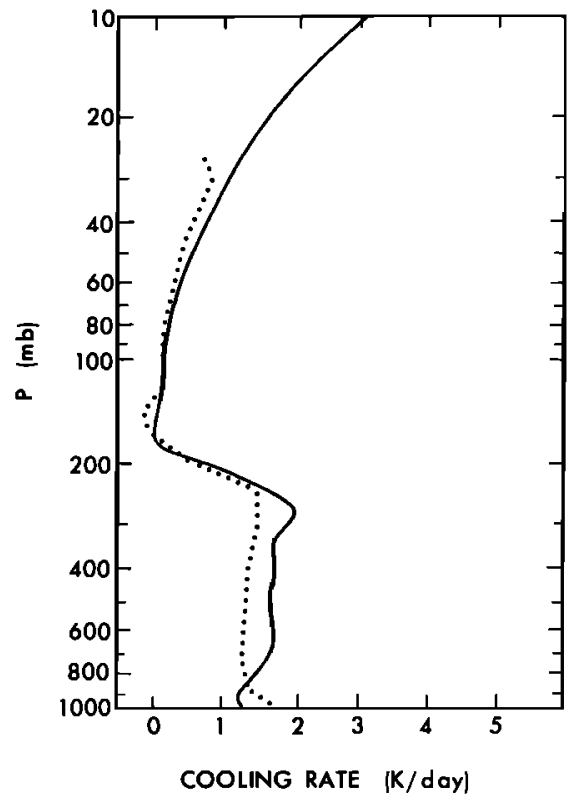

Fig. 14. Cooling rates for the MS profile. The gaseous absorbers are $\mathrm{H}_{2} \mathrm{O}$ (without continuum), $\mathrm{CO}_{2}$, and $\mathrm{O}_{3}$. The solid line gives the IAE result; the dotted line the ITF result.

Calculations of Gorchakova and Feigelson [1984] indicate that $\vartheta$ is almost constant and has the values of $-5.5 \mathrm{~W} / \mathrm{m}^{2}$ for the TR case, $-4.3 \mathrm{~W} / \mathrm{m}^{2}$ for the MS case, and $-3.3 \mathrm{~W} / \mathrm{m}^{2}$ for the SW case.

\section{Summary and Conclusions}

A technique for calculation of longwave transmissivities, fluxes, and cooling rates using an LBL technique has produced results in general agreement with other LBL results given in the WCP-93 document [Luther, 1984]. We have tested a number of methods for handling the vertical temperature stratification observed in the atmosphere; our tests indicate that errors of several $\mathrm{W} / \mathrm{m}^{2}$ may be made if an improper vertical quadrature scheme is employed in these calculations.

Wideband models, such as the one described in section 3, obtain fluxes to an accuracy of about $5 \%$. The ITF model

TABLE 12. Sensitivity of the Flux Calculation in the ITF and

\begin{tabular}{|c|c|c|c|c|c|c|c|c|}
\hline \multirow{2}{*}{$\begin{array}{l}\text { Level, } \\
\text { km }\end{array}$} & \multicolumn{4}{|c|}{$\begin{array}{c}\text { Tropical-Mid-Latitude } \\
\text { Summer }\end{array}$} & \multicolumn{4}{|c|}{$\begin{array}{l}\text { Mid-Latitude Summer- } \\
\text { Subarctic Winter }\end{array}$} \\
\hline & $\Delta F_{e}^{+}$ & $\Delta \boldsymbol{F}^{+}$ & $\Delta F_{e}^{-}$ & $\Delta F^{-}$ & $\Delta F_{e}^{+}$ & $\Delta F^{+}$ & $\Delta F_{e}^{-}$ & $\Delta F^{-}$ \\
\hline 0 & 36 & 35 & 49 & 48 & 175 & 176 & 182 & 176 \\
\hline 3 & 21 & 21 & 25 & 28 & 133 & 135 & 97 & 91 \\
\hline 6 & 13 & 14 & 9 & 6 & 114 & 112 & 67 & 66 \\
\hline 9 & 10 & 11 & 0 & 0 & 101 & 92 & 34 & 32 \\
\hline 13 & 11 & 7 & -3 & 0 & 86 & 81 & 1 & -2 \\
\hline 15 & 9 & 7 & -5 & 1 & 84 & 77 & 2 & -4 \\
\hline 17 & 8 & 5 & -5 & 2 & 83 & 77 & 2 & -4 \\
\hline 20 & 7 & 3 & -2 & 2 & 85 & 78 & 3 & -2 \\
\hline
\end{tabular}
IAE Methods to a Change in the Atmospheric Profile

The change is given in the top line of the table. $\Delta F_{e}$ refers to IAE flux sensitivities; $\Delta F$ (without subscript) refers to ITF sensitivities. Results are shown for upward $(+)$ and downward $(-)$ fluxes and are in $\mathrm{W} / \mathrm{m}^{2}$. 
discussed in section $\mathbf{4}$ has similar accuracy when flux values are in hundreds of $\mathrm{W} / \mathrm{m}^{2}$; for small flux values, however, ITF calculations are accurate only to within 1 order of magnitude. The sensitivity of these models to changes in initial atmospheric profiles reproduces the LBL sensitivities more closely than do the absolute fluxes themselves. Neglect of the temperature variation of absorption coefficients produces significant errors in the downward flux computations in the middle troposphere.

\section{REFERENCES}

Ackerman, S. A., and S. K. Cox, The Saudi Arabian heat low: Aerosol distribution and thermodynamic structure, J. Geophys. Res., 87, 8991-9002, 1982.

Bartman, F. L., W. R. Kuhn, and L. T. Loh, Low resolution measurement of ozone absorptivity in the $9.6 \mu \mathrm{m}$ region, $R e p$. 036350-1-F, 64 pp., Univ. of Mich., Ann Arbor, 1975.

Bulanin, M. O., and M. V. Tonkov, Investigation of the $\mathrm{CO}_{2}$ transmission in the 4.3 and $15 \mu \mathrm{m}$ bands, in Problems of Atmospheric Physics, Collected Papers, pp. 14-24, Leningrad University Press, USSR, 1976.

Davis, P. A., and W. Viezee, A model for computing infrared transmission through atmospheric water vapor and carbon dioxide, J. Geophys. Res., 69, 3785-3794, 1964.

Ellingson, R. G., and J. C. Gille, Correction of random exponential band transmission for Doppler effects, Appl. Opt., 7, 471-474, 1968.

Ellingson, R. G., and J. C. Gille, An infrared radiative transfer model, I, Model description and comparison of observation with calculation, J. Atmos. Sci., 35, 523-545, 1978.

Feigelson, E. M., Radiant Heat Transfer in a Cloudy Atmosphere, Gidrometeoizdat, Leningrad, 1970. (English translation, Keter Press, Jerusalem, 1973.)

Feigelson, E. M., and L. R. Dmitrieva (Eds.), Radiative algorithms in the atmospheric general circulation models: A review, Inf. VNIGMI-MCD, issue 1, Obninsk, 1983.

Fomin, B. A., I. I. Kuz'min, and A. N. Trotsenko, An effective line-by-line method of calculating the IR radiation absorption in gases, Prep. IAE-4070/I, 16 pp., CNIIatominform, Moscow, 1984.

Galtsev, A. P., I. A. Gorchakova, A. N. Trotsenko, E. M. Feigelson, and B. A. Fomin, Calculations of thermal radiation fluxes by the line-by-line and integral methods, Izv. Akad. Nauk. SSSR Fiz. Atmos. Okeana, 23, 39-44, 1987. (Izv. USSR Acad. Sci. Phys. Atmos. Ocean, Engl. Transl., 23, 28-31, 1987.)

Goldman, A., F. S. Bonomo, and D. G. Murcray, Statistical band model analysis and integrated intensity for the $11.8 \mu \mathrm{m}$ band of $\mathrm{CFCl}_{3}$, Appl. Opt., 15, 2305-2307, 1976 a.

Goldman, A., F. S. Bonomo, and D. G. Murcray, Statistical band model analysis and integrated intensity for the $10.8 \mu \mathrm{m}$ band of $\mathrm{CF}_{2} \mathrm{Cl}_{2}$, Geophys. Res. Lett., 3, 309-312, 1976 b.

Goody, R. M., Atmospheric Radiation, Part I, Theoretical Basis, 436 pp., Clarendon, Oxford, 1964.

Gorchakova, I. A., and E. M. Feigelson, On the comparability of the calculated and measured thermal radiation fluxes, Izv. Acad. Nauk SSSR Fiz. Atmos. Okeana, 18, 905-915, 1982. (Izv. USSR Acad. Sci. Phys. Atmos. Ocean, Engl. Transl., 18, 699-707, 1982.)

Gorchakova, I. A., and E. M. Feigelson, Some estimates of anthropogenic effect on the thermal radiation and climate, Izv. Akad. Nauk SSSR Fiz. Atmos. Okeana, 20,1128-1131, 1984. (Izv. USSR Acad. Sci. Phys. Atmos. Ocean, Engl. Transl., 20, 958-961, 1984.)

Kondratyev, K. Ya., and Yu. M. Timofeyev, Direct methods of calculating the transmission functions of atmospheric gases, $I z v$. Akad. Nauk SSSR Fiz. Atmos. Okeana, 3, 198-206, 1967. (Izv. USSR Acad. Sci. Phys. Atmos. Ocean, Engl. Transl., 3, 112-116, 1967.)

Kondratyev, K. Ya., and Yu. M. Timofeyev, Thermal Sounding of the Atmosphere From Satellites, Gidrometeoizdat, Leningrad, 1970.

Kondratyev, K. Ya., and Yu. M. Timofeyev, Meteorological Sounding of the Atmosphere From Space, Gidrometeoizdat, Leningrad, 1978.
Kunde, V. G., and W. C. Maguire, Direct integration transmittance model, J. Quant. Spectrosc. Radiat. Trans., 14, 803, 1974.

Luther, F. M., The intercomparison of radiation codes in climate models (ICRCCM) - Longwave clear-sky calculations, Rep. WCP-93, World Clim. Programme, World Meteorol. Organ., Geneva, 1984.

Luther, F. M., R. G. Ellingson, Y. Fouquart, S. B. Fels, N. Scott, and $\mathbf{W}$. J. Wiscombe, Intercomparison of radiation codes in climate models (ICRCCM): Longwave clear-sky results-A workshop summary, Bull. Am. Meteorol. Soc., 69, 40-48, 1988.

Matveyev, V. S., Approximate representations of the absorption coefficient and equivalent line width with the Voigt line shape, $J$. Appl. Spectrosc. USSR, 16, 228-233, (Eng. 168-172), 1972.

McClatchey, R. A., W. Fenn, J. E. A. Selby, F. E. Volz, and J. S. Garing, Optical properties of the atmosphere, Rep. AFCRL-720497, Air Force Cambridge Res. Lab., Hanscom, Air Force Base, Bedford, Mass., 1972.

McClatchey, R. A., W. S. Benedict, S. A. Clough, D. E. Burch, R. F. Calfee, K. Fox, L. S. Rothman, and J. S. Garing, AFCRL atmospheric absorption line parameters compilation, Rep. AFCRL-TR-73-0096, 83 pp., Air Force Cambridge Res. Lab., Hanscom Air Force Base, Bedford, Mass., 1973.

Minis, P., and S. K. Cox, A polynomial representation of $6.3 \mu \mathrm{m}$ water vapor and $4.3 \mu \mathrm{m} \mathrm{CO} \mathrm{CO}_{2}$ atmospheric transmissivities, $A t$ mos. Sci. Pap. 264, 37 pp., Colo. State Univ., Fort Collins, 1976.

Mokhov, I. I., On the effect of $\mathrm{CO}_{2}$ on the thermal regime of the earth's climatic system, Meteorol. Gidrol., 4, 24-34, 1981. (Meteorol. Hydrol. USSR, Engl. Transl., 4, 17-26, 1981.)

Morcrette, J. J., and Y. Fouquart, On systematic errors in parameterized calculations of longwave radiation transfer, $Q . J . R$. Meteorol. Soc., 111, 691-708, 1985.

Moskalenko, N. I., Experimental investigations of the spectral transparency of the vapors of $\mathrm{H}_{2} \mathrm{O}, \mathrm{CO}_{2}, \mathrm{CH}_{4}, \mathrm{NO}, \mathrm{CO}$ under conditions of an artificial atmosphere, Izv. Akad. Nauk SSSR Fiz. Atmos. Okeana, 5, 962-966, 1969. (Izv. USSR Acad. Sci. Phys. Atmos. Ocean, Engl. Transl., 5, 552-555, 1969.)

Moskalenko, N. I., On radiation absorption in the $\mathrm{HNO}_{3}$ bands, Izv . Akad. Nauk SSSR Fiz. Atmos. Okeana, 8, 234-235, 1972. (Izv. USSR Acad. Sci. Phys. Atmos. Ocean, Engl. Transl., 8, 133-134, 1972.)

Moskalenko, N. I., and S. O. Mirumiantz, On the spectral and integral absorption in the $5.3 \mu \mathrm{m}$ NO band, Izv. Akad. Nauk SSSR Fiz. Atmos. Okeana, 6, 115-116, 1970. (Izv. USSR Acad. Sci. Phys. Atmos. Ocean, Engl. Transl., 6, 208-209, 1970.)

Moskalenko, N. I., O. V. Zotov, and S. O. Mirumiantz, IR radiation absorption by ammonia in the $0.8-25 \mu \mathrm{m}$ region, Izv. Akad. Nauk SSSR Fiz. Atmos. Okeana, 8, 477-478, 1972. (Izv. USSR Acad. Sci. Phys. Atmos. Ocean, Engl. Transl., 8, 208, 1972.)

Nijlisk, H. Yu., and L. E. Sammel, Atmospheric integral transmission function for calculating the thermal radiation field in the troposphere, in Collected Papers: Tables of Atmospheric Radiative Characteristics, pp. 128-180, Academy of Science, Estonia, and Institute of Physics and Astronomy, Tartu, USSR, 1969.

Pugh, L., and N. Rao, Intensities for infrared spectra, Mol Spectrosc. Modern Res., 2, 312 pp., 1976.

Ridgway, W. L., Harshvardhan, and A. Arking, Computation of atmospheric infrared cooling rates by exact and approximate methods, J. Geophys. Res., this issue.

Roberts, R. E., J. E. A. Selby, and L. M. Biberman, Infrared continuum absorption by atmospheric water vapor in the 8-12 $\mu \mathrm{m}$ window, Appl. Opt., IS, 2085-2090, 1976.

Rodgers, C. D., and C. D. Walshaw, The computation of infrared cooling rate in planetary atmospheres, $Q . J . R$. Meteorol. Soc., 92, 67-92, 1966.

Rothman, L. S., Atmospheric absorption line parameters compilation: 1980 version, Appl. Opt., 20, 791-795, 1981.

Rothman, L. S., et al., The HITRAN data base: 1986 edition, Appl. Opt., 26, 4058-4097, 1987.

Rozanov, E. V., Yu. M. Timofeyev, and V. A. Frolkis, The influence of some minor gaseous constituents on the radiation regime of the atmosphere in the IR range, Izv. Akad. Nauk SSSR Fiz. Atmos. Okeana, 17, 384-391, 1981. (Izv. USSR Acad. Sci. Phys. Atmos. Ocean, Engl. Transl., 17, 277-282, 1981.)

Schwarzkopf, M. D., and S. B. Fels, The simplified exchange method revisited: An accurate, rapid method for computation of infrared cooling rates and fluxes, J. Geophys. Res., this issue. 
Smith, W. L., A polynomial representation of carbon dioxide and water vapor transmission, ESSA Tech. Rep. NESC, 47, 20 pp., Natl. Environ. Satellite Cent., Washington, D. C., 1969.

Stull, V. R., P. J. Wyatt, and G. N. Plass, The infrared absorption of carbon dioxide, Infrared Transm. Stud Rep., vol. III, Los Angeles, Calif., 1963.

Trotsenko, A. N., and B. A. Fomin, A direct integration method in the problem of the longwave radiation transfer in homogeneous gaseous media, Prep. IAE-4289/1, 12 pp., CNIIatominform, Moscow, 1986.

Trotsenko, A. N., and B. A. Fomin, Direct integration method in the problem of thermal radiation transfer in inhomogeneous media, Prep. IAE-4424/l, 16 pp., CNIlatominform, Moscow, 1987.

Wyatt, P. J., V. R. Stull, and G. N. Plass, The infrared absorption of water vapor, Infrared Transm. Stud. Rep. SSD-TDR-62-127, Los Angeles, Calif., vol. II, 1962.
E. M. Feigelson and I. A. Gorchakova, Institute of Atmospheric Physics, Academy of Science, Pazhevsky, 3 Moscow ZH17, USSR.

B. A. Fomin and A. N. Trotsenko, Kurchatov Institute of Atomic Energy, Molecular Physics Department, 123182 Moscow, USSR.

E. V. Rozanov, Main Geophysical Observatory, Leningrad, USSR.

M. D. Schwarzkopf, GFDL/NOAA, P. O. Box 308, Princeton, N. J. 08542

Yu. M. Timofeyev, Institute of Physics, Leningrad State University, Leningrad, USSR.

(Received March 22, 1990; revised February 11, 1991: accepted February 12, 1991.) 